\title{
Aerothermodynamic Environments Definition for the Mars Science Laboratory Entry Capsule
}

\author{
Karl T. Edquist ${ }^{\dagger}$ \\ NASA Langley Research Center, Hampton, Virginia, 23681 \\ Artem A. Dyakonov* \\ National Institute of Aerospace, Hampton, Virginia, 23666 \\ Michael J. Wright ${ }^{\ddagger}$ \\ NASA Ames Research Center, Moffett Field, CA 94035 \\ Chun Y. Tang ${ }^{\S}$ \\ ELORET Corporation, Moffett Field, CA 94035
}

\begin{abstract}
An overview of the aerothermodynamic environments definition status is presented for the Mars Science Laboratory entry vehicle. The environments are based on Navier-Stokes flowfield simulations on a candidate aeroshell geometry and worst-case entry heating trajectories. Uncertainties for the flowfield predictions are based primarily on available ground data since Mars flight data are scarce. The forebody aerothermodynamics analysis focuses on boundary layer transition and turbulent heating augmentation. Turbulent transition is expected prior to peak heating, a first for Mars entry, resulting in augmented heat flux and shear stress at the same heatshield location. Afterbody computations are also shown with and without interference effects of reaction control system thruster plumes. Including uncertainties, analysis predicts that the heatshield may experience peaks of 225 $\mathrm{W} / \mathrm{cm}^{2}$ for turbulent heat flux, $0.32 \mathrm{~atm}$ for stagnation pressure, and 400 Pa for turbulent shear stress. The afterbody heat flux without thruster plume interference is predicted to be $7 \mathrm{~W} / \mathrm{cm}^{2}$ on the backshell and $10 \mathrm{~W} / \mathrm{cm}^{2}$ on the parachute cover. If the reaction control jets are fired near peak dynamic pressure, the heat flux at localized areas could reach as high as $76 \mathrm{~W} / \mathrm{cm}^{2}$ on the backshell and $38 \mathrm{~W} / \mathrm{cm}^{2}$ on the parachute cover, including uncertainties. The final flight environments used for hardware design will be updated for any changes in the aeroshell configuration, heating design trajectories, or uncertainties.
\end{abstract}

\section{Nomenclature}

a speed of sound $(\mathrm{m} / \mathrm{s})$

B-L Baldwin-Lomax algebraic turbulence model

$\mathrm{C}_{\mathrm{D}} \quad$ drag coefficient, $D / 1 / 2 \rho_{\infty} V_{\infty}{ }^{2}$

D aeroshell diameter $(\mathrm{m})$

FPA flight path angle (deg)

$\mathrm{h} \quad$ altitude above reference ground level $(\mathrm{km})$

L/D lift-to-drag ratio

MSL Mars Science Laboratory

$\mathrm{m} \quad$ entry mass $(\mathrm{kg})$

$\mathrm{m} / \mathrm{C}_{\mathrm{D}} \mathrm{S}_{\mathrm{ref}}$ ballistic coefficient $\left(\mathrm{kg} / \mathrm{m}^{2}\right)$

\footnotetext{
${ }^{\top}$ Aerospace Engineer, Exploration Systems Analysis Branch, Mail Stop 489, AIAA Senior Member.

* Aerospace Engineer, Exploration Systems Analysis Branch, Mail Stop 489, AIAA Member.

* Senior Research Scientist, Reacting Flow Environments Branch, Mail Stop 230-2, AIAA Senior Member.

${ }^{\S}$ Senior Research Scientist, Reacting Flow Environments Branch, Mail Stop 230-2, AIAA Member.
} 


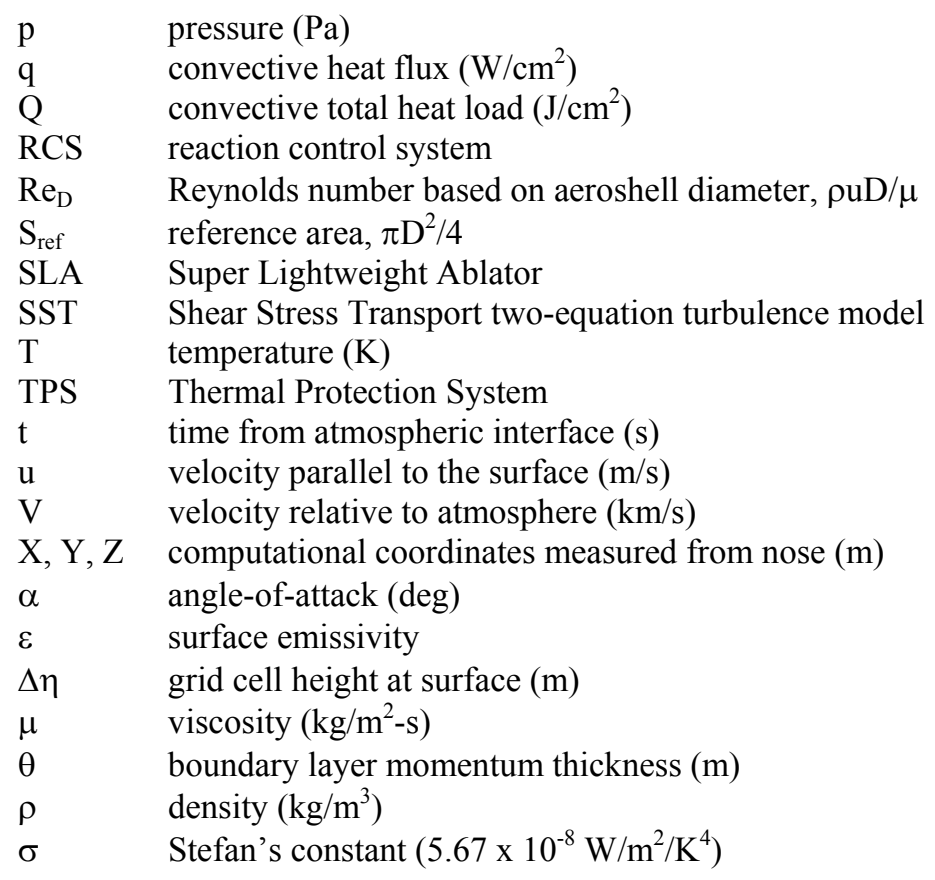

\section{Subscripts}

$\begin{array}{ll}\text { Design } & \text { aerothermodynamic condition used for TPS design } \\ \mathrm{e} & \text { boundary layer edge } \\ \text { ind } & \text { indicator } \\ \mathrm{W} & \text { wall } \\ \infty & \text { freestream }\end{array}$

\section{Introduction}

$\mathrm{T}$ Mars Science Laboratory (MSL) will land a large rover $(>800 \mathrm{~kg})$ with a footprint smaller than $10 \mathrm{~km}$ at a site of particular scientific interest between $+/-60$ degrees latitude and up to $1 \mathrm{~km}$ above the reference altitude ${ }^{1,2}$. The landing footprint is smaller and elevation higher than past successful missions using unguided lift-up (Viking 1 and 2) or ballistic (Mars Pathfinder, Mars Exploration Rovers A and B) entries. MSL will achieve improved landing accuracy and higher altitude by using a guidance algorithm to control the aerodynamic lift vector direction and mitigate uncertainties in predicted entry states, atmospheric properties, aerodynamics, etc. that lead to decreased performance. A hypersonic lift-to-drag ratio (L/D) of 0.24 at a trim angle-of-attack ( $\alpha$ ) of 16 degrees and ballistic coefficient $\left(\mathrm{m} / \mathrm{C}_{\mathrm{D}} \mathrm{S}_{\text {ref }}\right)$ of about $140 \mathrm{~kg} / \mathrm{m}^{2}$ are the expected entry conditions for a 2010 arrival. Ballast mass will be used to give the necessary radial center-of-gravity (CG) offset for the desired trim $\alpha$ and L/D.

The objective of this paper is to report the current status of the computational aerothermodynamics analysis for the MSL entry capsule. MSL will use a descendent of the rigid aeroshell and parachute decelerator system that has successfully landed payloads on Mars starting with Viking. However, MSL's aggressive entry strategy and large aeroshell will result in turbulent transition and unprecedented aerothermodynamic conditions (convective heat flux, surface pressure, and surface shear stress) compared to past successful Mars entries. A combination of high heating and shear stress occurring nearly at the same time and heatshield location stresses the thermal protection system (TPS) in ways that have not been tested or flown before. Also, the use of reaction control system (RCS) thrusters on the backshell may lead to unprecedented heating that requires a more capable TPS. Significant effort has been made to quantify the aerothermodynamic environments imposed on the entry capsule during hypersonic flight. References 4-11 contain computational and experimental aerothermodynamics analyses to date for various MSL entry vehicle configurations and design trajectories. Topics include transition and turbulent heating augmentation ${ }^{3}$, alternative aeroshell shapes ${ }^{4}$, afterbody heating ${ }^{5}$, and experimental studies in perfect gas and high-enthalpy facilities ${ }^{6-11}$. Refer to those papers for detailed descriptions of the MSL computational and experimental analyses to date. 


\section{Analysis}

There exist no ground-based facilities that can reproduce the hypersonic (Mach $>20$ ) and high-temperature $\mathrm{CO}_{2}-\mathrm{N}_{2}$ reactions that occur at Mars flight conditions. In addition, few relevant engineering data have been collected from past successful entries into the Martian atmosphere ${ }^{12}$. Consequently, extensive use of Navier-Stokes computational fluid dynamics (CFD) is required to define the TPS flight design environments. Validation of the CFD tools is based on comparisons with perfect-gas and high-enthalpy tests such as those described in References 611. The following sections describe the current flight capsule and aerothermodynamic design trajectories, as well as brief discussions of the RCS, TPS, and CFD methods.

\section{A. Aeroshell Geometry and Design Trajectories}

The primary decelerator for all Mars lander missions starting with Viking has been a rigid blunt body aeroshell; the same technology will be used for MSL. Table 1 summarizes the Viking-derived MSL capsule characteristics compared to past successful Mars missions and the upcoming Phoenix lander. A few key characteristics of MSL make it a much more aggressive and stressful atmospheric entry than has been previously attempted at Mars. First, MSL is much larger and heavier than any of the past entry capsules due to the large rover size. The MSL entry capsule is a 4.5 -meter diameter 70-deg spherically-blunted cone forebody with a triconic afterbody (Fig. 1). The rover mass alone is similar to the Mars Exploration Rover (MER) total entry system mass. Second, MSL will be designed to land at a higher elevation than has previously been attempted in order to access a wide range of latitudes for site selection. High landing elevation and precision landing for a high ballistic coefficient capsule requires flying at a higher angle-of-attack than has ever been flown. A high angle-of-attack contributes to augmented heating on both the heatshield (longer running length for turbulent transition) and backshell (attached flow).

Table 1. Comparison of Mars Entry Capsules

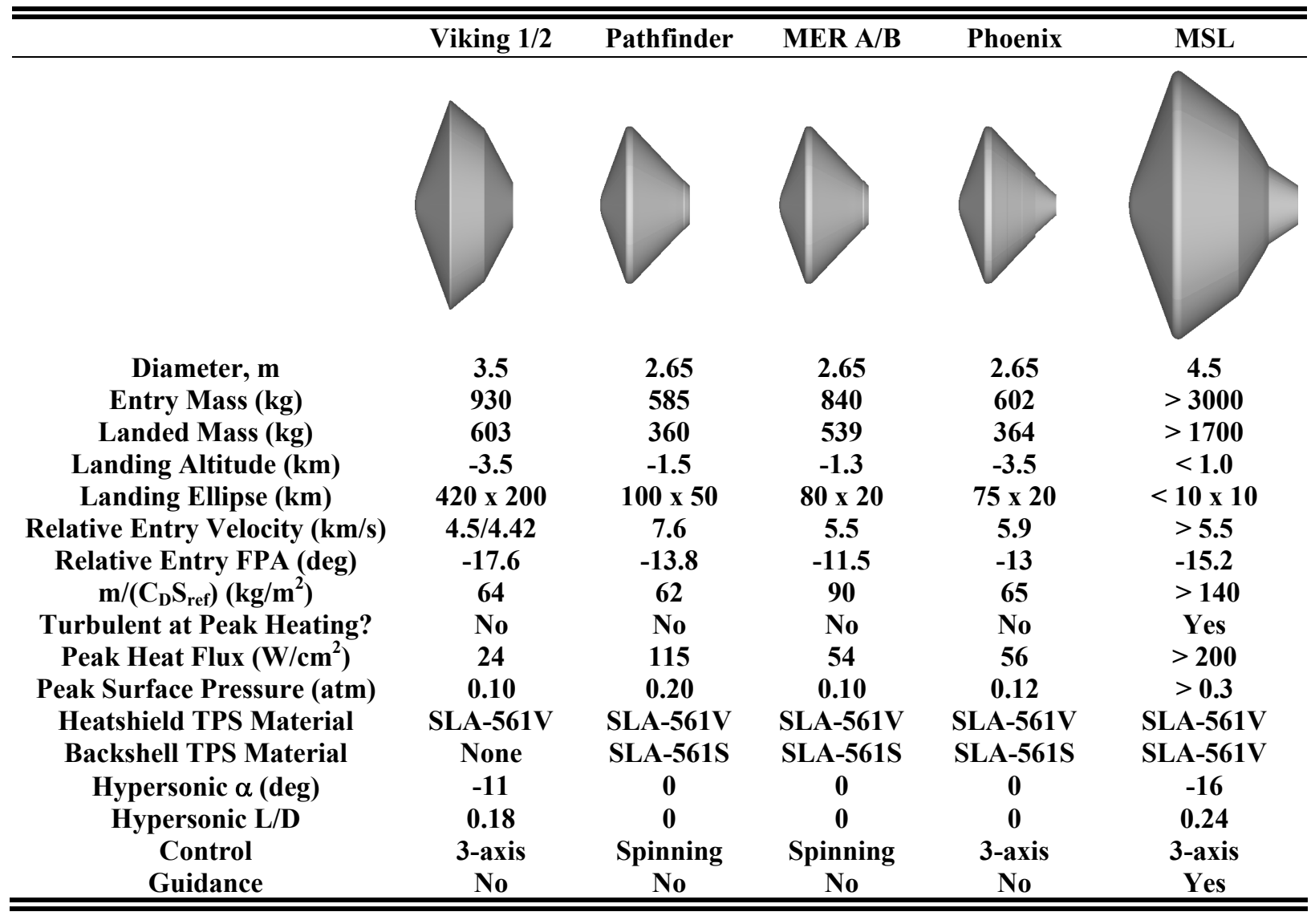


The large MSL capsule and aggressive entry lead to a highly stressful atmospheric trajectory. Figure 2 compares the MSL nominal trajectory to previous successful Mars entries and the upcoming Phoenix mission. Although the entry velocity is not especially high, MSL's larger ballistic coefficient leads to higher velocities at lower altitudes compared to all previous entries. MSL's high velocity at low altitudes (high density) will result in higher dynamic pressure (surface pressure) and Reynolds number (higher likelihood of turbulent transition) than have been experienced before. Both characteristics will lead to more severe aerothermodynamic conditions than any previous Mars entry capsule has experienced.

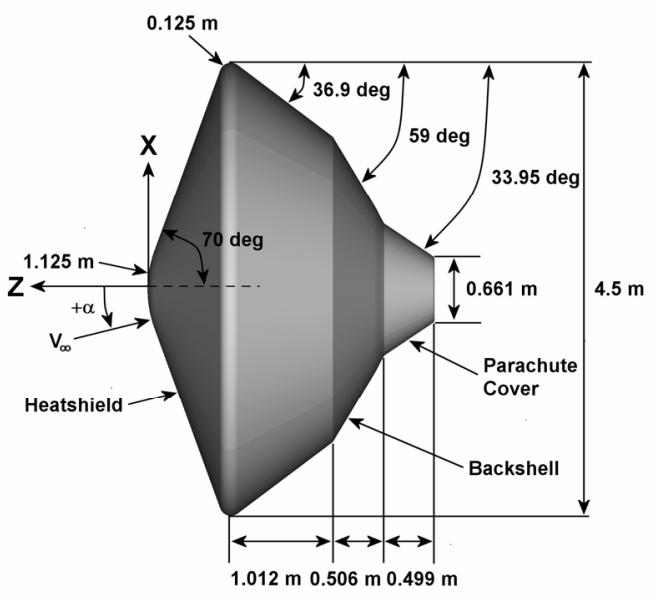

Figure 1. MSL Aeroshell Geometry

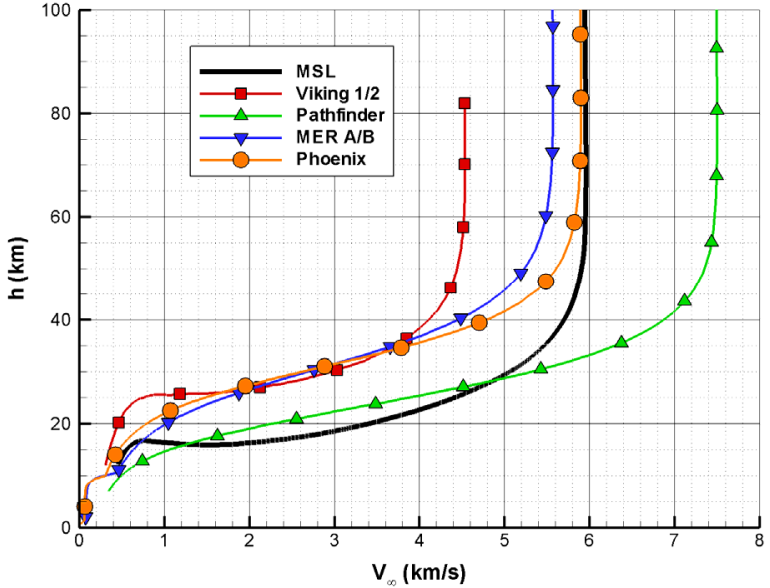

Figure 2. MSL Entry Trajectory Compared to Other Mars Missions

The MSL trajectory shown in Figure 2 is the nominal, or expected, entry path for the current entry system design and launch/arrival dates. The aerothermodynamic design trajectories are based on the nominal entry plus dispersions in the entry system, including navigated entry states, aerodynamic coefficients, and atmospheric density. A Monte-Carlo analysis was performed to identify trajectories that stress various systems, including the TPS. It is known that high entry velocity and high density will augment the aerothermal environments. The MSL heating design trajectory was identified as having a high entry velocity within the possible arrival dates. In addition, the arrival time of season was chosen to coincide near the maximum of the atmospheric pressure cycle. Within those constraints, the Monte-Carlo trajectories that result in $99.87 \%(+3 \sigma$ high) peak heat flux and total integrated heat load were chosen to determine the flight environments for TPS design purposes.

Normally, stagnation point heat flux using a Sutton-Graves formula ${ }^{13}$ is sufficient to estimate the maximum laminar heat flux for a spherically-blunted body. However, it will be shown later that MSL is expected to experience boundary layer transition early in the entry trajectory due to the large ballistic coefficient, large aeroshell, and relatively high angle-of-attack. Instead, the turbulent heat flux was estimated in the Monte-Carlo analysis using a heat flux indicator analogous to the Sutton-Graves formula. The indicator is simply a curve fit of CFD peak forebody heat flux predictions expressed as a function of freestream density and velocity:

$$
q_{\text {ind }}=C \rho_{\infty}{ }^{m} V_{\infty}^{n}\left(\frac{W}{\mathrm{~cm}^{2}}\right)
$$

The coefficients $C\left(8.53 \times 10^{-13}\right), m(0.830)$, and $n$ (4.512) were determined using the methods described in Reference 14. This method of fitting heat flux to freestream density and velocity was first demonstrated in Reference 15 and has been extended for MSL to estimate turbulent heat flux. Figure 3 shows the turbulent heat flux indicator (Eqn. 1) for the nominal and $+3 \sigma$ heating trajectories, not including uncertainties. The maximum heat flux estimate is $134 \mathrm{~W} / \mathrm{cm}^{2}$ for nominal entry and $156 \mathrm{~W} / \mathrm{cm}^{2}$ for the $+3 \sigma$ heat flux trajectory. The maximum total heat load estimate is $3840 \mathrm{~J} / \mathrm{cm}^{2}$ for the nominal entry and $4000 \mathrm{~J} / \mathrm{cm}^{2}$ for the $+3 \sigma$ heat load trajectory. These estimates were used only to identify heating design trajectories within the entry system design space. Experience has shown 
that the heat flux indicator is generally within $10 \%$ of CFD results. Detailed CFD results with uncertainties are shown in a later section.

\section{B. Thermal Protection and Reaction Control Systems}

The TPS material selected for the MSL heatshield and backshell is Super-Lightweight Ablator (SLA) 561V. SLA-561V has been implemented successfully for all past Mars heatshields, which experienced less severe conditions than are expected for MSL (see Table 1). SLA-561V is a lightweight ablative material made of ground cork, silica, and phenolic microspheres in a silicone binder. A spray-on version (SLA-561S) has been used on the backshells of previous capsules, where the environments are less severe. See Reference 16 for a description of the Mars Pathfinder heatshield TPS design using SLA-561V. Figure 4 shows the TPS material distribution, with SLA-561V for the heatshield

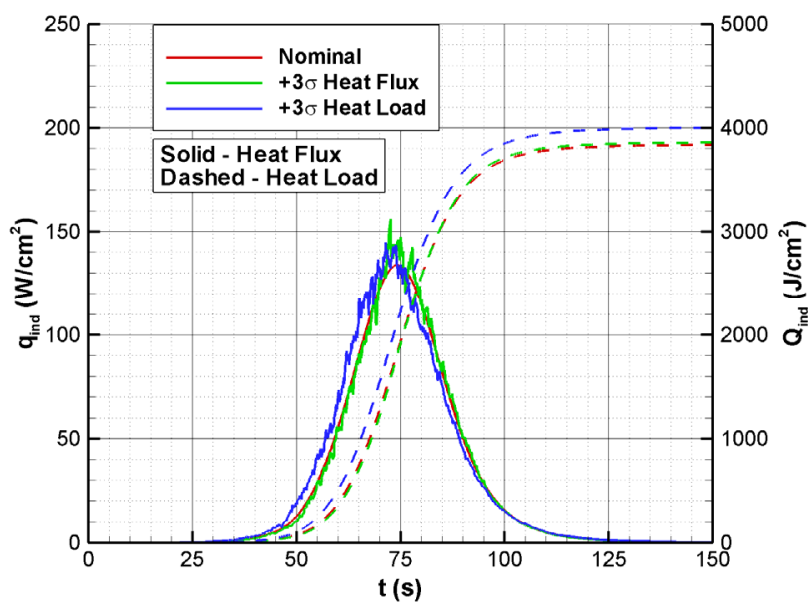

Figure 3. Turbulent Heat Flux and Total Heat Load Indicators for the Nominal, $+3 \sigma$ Heat Flux, and $+3 \sigma$ Heat Load Trajectories (No Uncertainties) and backshell, and Accusil II for the parachute cover.

The backshell TPS design will have to account for the effects of RCS thrusters on the surface environments. Figure 5 shows the current 4-pod RCS configuration designed to control attitudes in all three axes. Each pod will have a pair of $300-\mathrm{N}$ thrusters that fire simultaneously to perform coordinated pitch/yaw banking maneuvers during entry. The current windside RCS nozzle location and pointing direction result in the interaction of supersonic plume and wake flowfields. The interaction effects on the aerothermodynamic environments have been estimated using CFD methods and are presented in the results section. Based on those results, the use of SLA-561V is required on the backshell to withstand the RCS-induced conditions. MSL will be the first Mars capsule to use SLA-561V on the backshell.

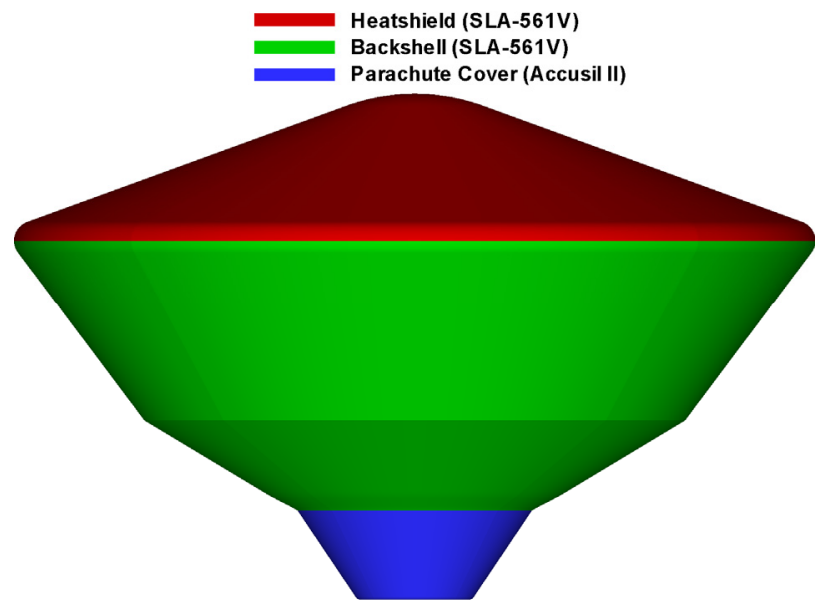

Figure 4. TPS Materials

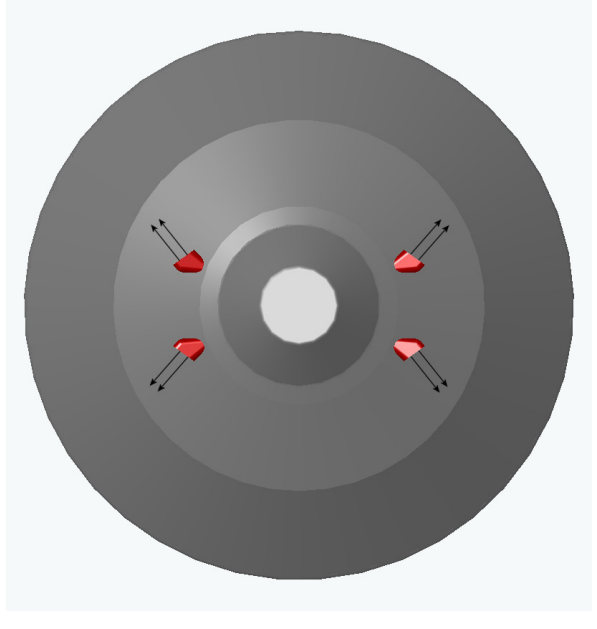

Figure 5. RCS Thruster Locations and Pointing Directions

\section{Computational Approach}

Navier-Stokes solutions of the MSL flowfield at flight conditions have been generated for the design trajectories using two different CFD codes. Following is a description of the codes' capabilities and computational grids used for the analyses with and without RCS thrusters. 


\section{LAURA CFD Code}

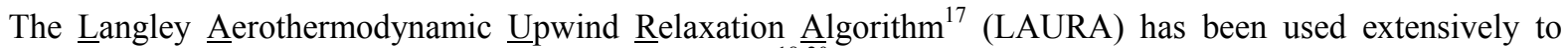
predict the aeroheating environments for Mars applications ${ }^{18-20}$. For Mars flight conditions, LAURA models an 8species Mars gas $\left(\mathrm{CO}_{2}, \mathrm{CO}, \mathrm{N}_{2}, \mathrm{O}_{2}, \mathrm{NO}, \mathrm{C}, \mathrm{N}, \mathrm{O}\right)$ in chemical and thermal non-equilibrium using the Park-94 ${ }^{21}$ reaction rates. A finite-volume approach is used to solve the full Navier-Stokes flowfield equations for all calculations presented here. The code uses Roe's averaging ${ }^{22}$ for the inviscid fluxes with second-order corrections using Yee's symmetric total variation diminishing (TVD) scheme ${ }^{23}$. Turbulent LAURA solutions were obtained with the Baldwin-Lomax algebraic model ${ }^{24,25}$. The model is believed to provide reliable turbulent heating predictions for attached flow as is the case for the MSL heatshield.

LAURA possesses the capability to adapt the computational mesh to the boundary layer and bow shock through user-defined parameters. Proper mesh resolution at the wall is especially important for reliable heating predictions. In LAURA, a user-specified cell Reynolds number controls the grid spacing at the wall:

$$
R e_{w}=\left(\frac{\rho a \Delta \eta}{\mu}\right)_{w}
$$

Experience has shown ${ }^{4}$ that reliable heating predictions can be achieved with $R e_{w}=\mathrm{O}(1)$. Grid adaptations are executed throughout the solution process until further adaptations do not significantly change the heat flux.

A super-catalytic wall boundary condition was implemented to fix the mass fractions of $\mathrm{CO}_{2}$ and $\mathrm{N}_{2}$ to their freestream values of 0.97 and 0.03 , respectively. This boundary condition results in conservative heating predictions in flight. A radiative-equilibrium wall temperature was specified to satisfy the following relation:

$$
q_{w}=\varepsilon \sigma T_{w}^{4}
$$

A fixed surface emissivity $(\varepsilon)$ of 0.89 was used for all solutions. The wall is assumed to radiate to a temperature of absolute zero. All heating results reported here are convective only and neglect heating due to shock layer radiation. This assumption is appropriate given that the computed radiative heating at the peak heating point of the current design trajectory is less than $0.01 \mathrm{~W} / \mathrm{cm}^{2}$, as computed with the NEQAIR code ${ }^{26}$.

\section{DPLR CFD Code}

Data Parallel Line Relaxation ${ }^{27}$ (DPLR) solutions were run with essentially the same models and boundary conditions as were run with LAURA. DPLR is a parallel multi-block finite-volume code that solves the reacting Navier-Stokes equations including finite-rate chemistry and the effects of thermal non-equilibrium using the same species set as LAURA. The Euler fluxes are computed using a modified (low-dissipation) form of Steger-Warming flux vector splitting ${ }^{28}$ with third-order spatial accuracy obtained via MUSCL extrapolation coupled with a minmod limiter ${ }^{29}$. Viscous fluxes are computed to second-order accuracy using a central difference approach. Turbulent solutions were obtained using both the Baldwin-Lomax model and the two-equation Shear Stress Transport (SST) model of Menter ${ }^{30}$. The SST model is essentially a hybrid of the standard k- $\varepsilon$ and $k-\omega$ models, and has been shown by Brown ${ }^{31}$ to provide accurate simulations of a variety of supersonic and hypersonic flowfields. A super-catalytic wall boundary condition was employed with a surface emissivity of 0.89 for compatibility with the LAURA solutions. DPLR afterbody heating simulations have compared favorably to Earth entry flight data ${ }^{32,33}$.

\section{Computational Grids}

LAURA and DPLR flowfield solutions were obtained on structured computational grids with near-wall grid spacing specified to give a cell Reynolds number of $\mathrm{O}(1)$. Figure 6a shows the coarse surface grids (every other point in each direction) used for both codes without RCS thrusters. The nose and base grids are arranged to avoid a pole singularity point. The LAURA and DPLR volume grids were constructed using the surface grid shown in Figure 6a. The fine grid has 35840 surface cells and 4,587,520 volume cells (128 cells in the surface-normal direction). Although not shown, both the LAURA and DPLR solutions presented here are grid-converged and grid- 
independent. LAURA and DPLR solutions with RCS thrusters modeled were obtained on separate surface grids by cutting holes in the existing grid at the RCS location (Fig. 6b). Supersonic nozzle exit conditions were specified at the hole locations. A single hole was used to model each thruster pair and sized to generate the correct mass flux.
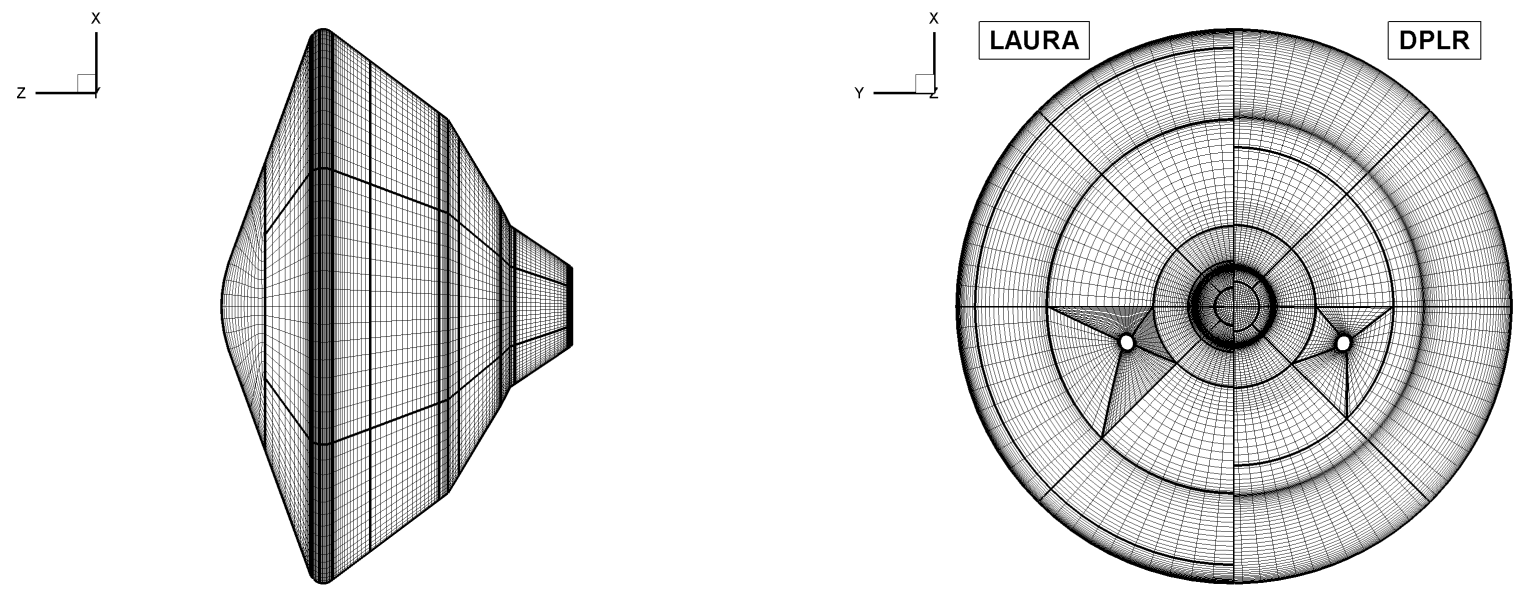

\section{a. Baseline Coarse Grid (Every Other Point Shown in Each Direction)}

\section{b. Backshell Grid With Windside RCS Thruster}

Figure 6. Computational Surface Grids

\section{CFD Solution Points}

Aerothermodynamic environments definition includes estimates for heat flux, surface pressure, shear stress, and total heat load. Peak heat flux is used to select a TPS material that can survive that level of heating. Integrated total heat load determines the required thickness to keep the bondline temperature below a critical level $\left(250^{\circ} \mathrm{C}\right.$ for the heatshield, $150^{\circ} \mathrm{C}$ for the backshell and parachute cover). In order to determine these two heating quantities, CFD solutions on both the $+3 \sigma$ Heat Flux and Heat Load trajectories are required. See Figure 7 for the CFD solution point locations. Three solutions were run on the $+3 \sigma$ Heat Flux trajectory, including one at peak forebody turbulent heat flux and another at peak freestream dynamic pressure. Peak afterbody heat flux for MSL occurs near peak dynamic pressure and after the forebody heating has reached its peak value. A series of solutions were run on the

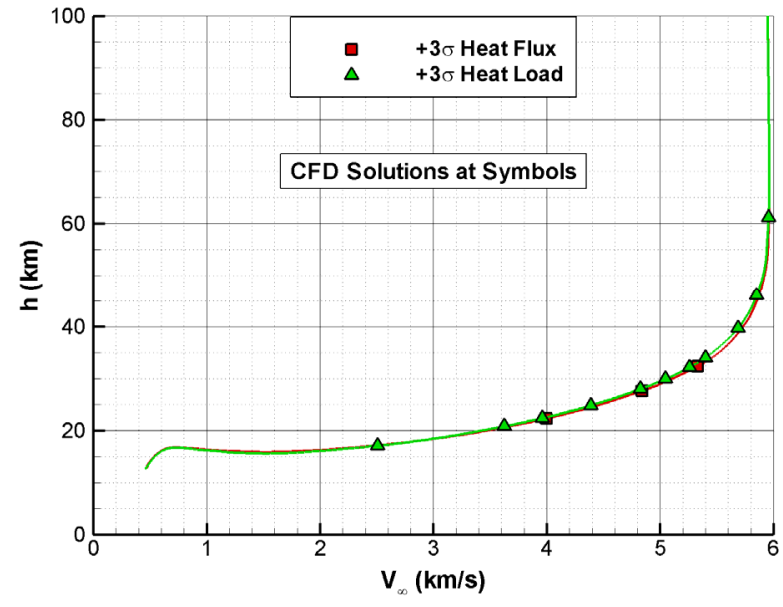

a. Altitude vs. Relative Velocity

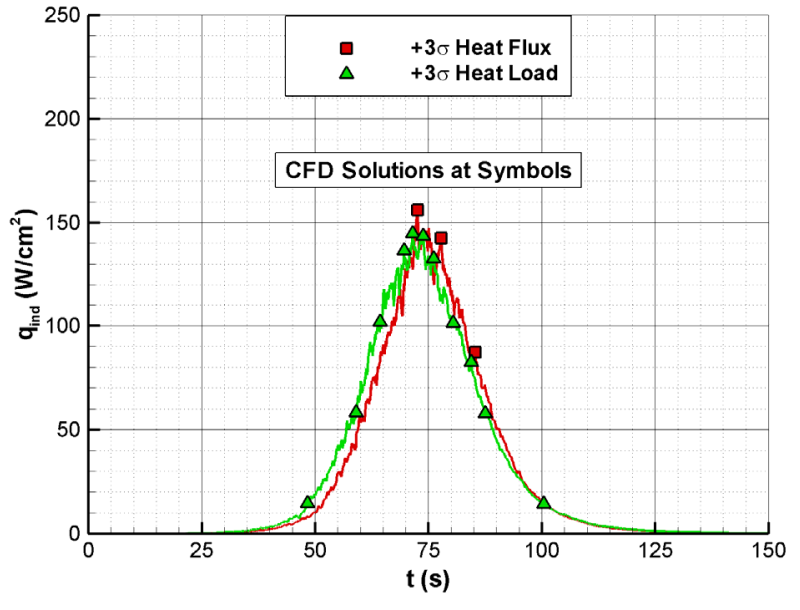

b. Turbulent Heat Flux Indicator vs. Time (No Uncertainty)

Figure 7. CFD Solution Points on the $+3 \sigma$ Heat Flux and $+3 \sigma$ Heat Load Trajectories 
$+3 \sigma$ Heat Load trajectory, the results of which were integrated over time to obtain total heat load. Both LAURA and DPLR solutions were obtained at freestream conditions shown in Table 2. Turbulent solutions for the heatshield were run using the Baldwin-Lomax algebraic model (LAURA, DPLR) and SST model (DPLR). Laminar solutions were obtained with both codes to predict backshell and parachute cover conditions.

Table 2. Freestream Conditions for CFD Solutions on $+3 \sigma$ Heat Flux and Heat Load Trajectories

\begin{tabular}{ccccccccc}
\hline \hline Trajectory & $\mathrm{t}(\mathrm{s})$ & $\mathrm{h}(\mathrm{km})$ & $\mathrm{V}_{\infty}(\mathrm{km} / \mathrm{s})$ & $\rho_{\infty}\left(\mathrm{kg} / \mathrm{m}^{3}\right)$ & $\mathrm{T}_{\infty}(\mathrm{K})$ & Mach & $\mathrm{Re}_{\mathrm{D}} \times 10^{-6}$ & $\alpha(\mathrm{deg})$ \\
\hline$+3 \sigma \mathrm{HF}$ & 72.6 & 32.4 & 5.33 & $0.84 \times 10^{-3}$ & 163 & 28.6 & 2.46 & 16.8 \\
$+3 \sigma \mathrm{HF}$ & 77.8 & 27.6 & 4.84 & $1.27 \times 10^{-3}$ & 173 & 24.4 & 3.18 & 16.7 \\
$+3 \sigma \mathrm{HF}$ & 85.3 & 22.3 & 4.00 & $1.99 \times 10^{-3}$ & 182 & 19.1 & 3.90 & 17.0 \\
\hline$+3 \sigma \mathrm{HL}$ & 48.4 & 61.2 & 5.96 & $2.61 \times 10^{-5}$ & 137 & 32.9 & 0.11 & 17.3 \\
$+3 \sigma \mathrm{HL}$ & 59.1 & 46.0 & 5.85 & $1.54 \times 10^{-4}$ & 145 & 29.1 & 0.57 & 17.3 \\
$+3 \sigma \mathrm{HL}$ & 64.4 & 39.7 & 5.69 & $3.51 \times 10^{-4}$ & 158 & 28.7 & 1.14 & 17.3 \\
$+3 \sigma \mathrm{HL}$ & 69.6 & 34.0 & 5.40 & $6.63 \times 10^{-4}$ & 172 & 26.8 & 1.87 & 17.2 \\
$+3 \sigma \mathrm{HL}$ & 71.5 & 32.2 & 5.26 & $8.22 \times 10^{-4}$ & 177 & 26.1 & 2.19 & 17.1 \\
$+3 \sigma \mathrm{HL}$ & 73.9 & 29.9 & 5.05 & $1.02 \times 10^{-3}$ & 181 & 24.7 & 2.52 & 17.0 \\
$+3 \sigma \mathrm{HL}$ & 76.2 & 28.0 & 4.83 & $1.18 \times 10^{-3}$ & 185 & 23.0 & 2.74 & 17.0 \\
$+3 \sigma \mathrm{HL}$ & 80.5 & 24.8 & 4.39 & $1.43 \times 10^{-3}$ & 191 & 19.6 & 2.92 & 17.1 \\
$+3 \sigma \mathrm{HL}$ & 84.4 & 22.4 & 3.96 & $1.96 \times 10^{-3}$ & 195 & 18.4 & 3.52 & 17.3 \\
$+3 \sigma \mathrm{HL}$ & 87.5 & 20.8 & 3.62 & $2.06 \times 10^{-3}$ & 198 & 16.0 & 3.35 & 17.5 \\
$+3 \sigma \mathrm{HL}$ & 100.5 & 17.1 & 2.51 & $2.86 \times 10^{-3}$ & 204 & 11.0 & 3.11 & 18.2 \\
\hline \hline
\end{tabular}

\section{Results and Discussion}

Computational results using LAURA and DPLR are presented for both the heatshield and backshell, including the parachute cover. A brief discussion of uncertainties is followed by the design flight environments currently being used for TPS testing and design.

\section{A. Blunt Body Flowfield}

Hypersonic flow over a blunt body such as MSL contains many structures that make the flowfield computation challenging. Figure 8 shows a sample LAURA flowfield solution at peak dynamic pressure on the $+3 \sigma$ Heat Flux trajectory $(\mathrm{t}=85.3 \mathrm{~s})$. The bow shock at hypersonic speeds lies very close to the heatshield. At an angle-ofattack of about $17 \mathrm{deg}$, the heatshield stagnation point moves off the spherical nosecap and onto the "windside" flank. Pressure is highest at the heatshield stagnation point and falls off rapidly as the flow expands around the shoulder and onto the backshell. The relatively high angle-of-attack causes attached flow on parts of the backshell and parachute cover. The leeside backshell is within the shear layer and should experience less severe conditions than exist on the windside. Capturing the shear layer is critical to the quality of the wake solution and is sensitive to the computational grid. Much of the wake flowfield is unsteady and possibly turbulent, which makes its computation with steady-state Navier-Stokes codes less than ideal. Large Eddy Simulation methods may be more appropriate for the wake flowfield.

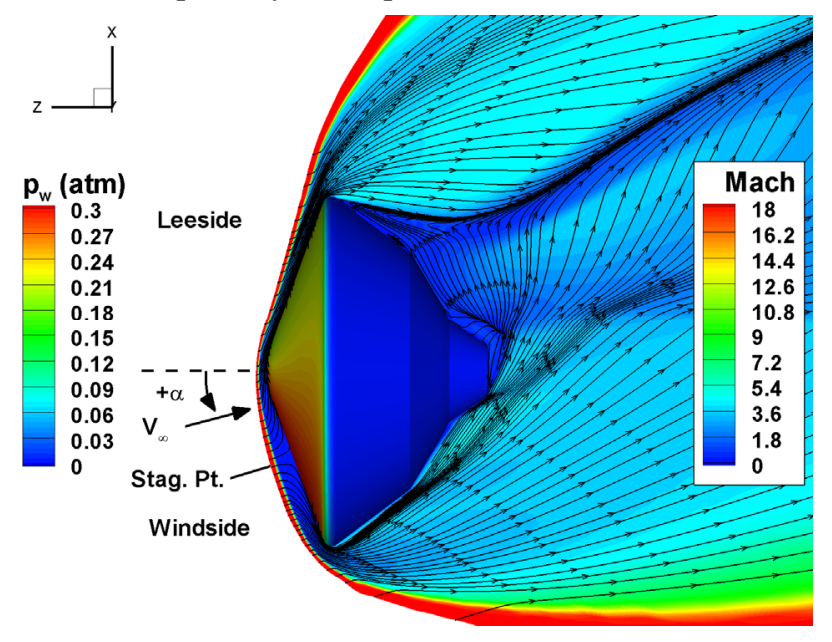

Figure 8. Symmetry Plane Cut of LAURA Mach Number and Surface Pressure on the $+3 \sigma$ Heat Rate Trajectory $(t=85.3 \mathrm{~s})$

8

American Institute of Aeronautics and Astronautics 


\section{B. Heatshield Environments}

All previous Mars entry capsules are believed to have experienced laminar conditions at the time of peak heating. In those cases, the maximum heat flux occurred on the nose cap and could be approximated with a formula such as Sutton-Graves. For MSL, a large ballistic coefficient and aeroshell diameter enhance the likelihood of boundary layer transition occurring prior to peak heating. Turbulent conditions increase the magnitude of both heating and shear, and change the location of their maxima. A rigorous turbulent transition analysis has not been performed for MSL. Rather, for TPS design purposes, a momentum-thickness Reynolds number $\left(R e_{\theta}\right)$ criterion of 200 was selected early in the MSL project to conservatively indicate the time for transition. $R e_{\theta}$ is defined as:

$$
\operatorname{Re}_{\theta}=\frac{\rho_{e} u_{e} \theta}{\mu_{e}}
$$

and boundary layer momentum-thickness is defined as:

$$
\theta=\int_{0}^{e} \frac{\rho u}{\rho_{e} u_{e}}\left(1-\frac{u}{u_{e}}\right) d \eta
$$

The boundary later edge conditions are defined where total enthalpy is $99.5 \%$ of the freestream value.

The time at which any portion of the heatshield $R e_{\theta}$ exceeds 200 is identified as the transition time. Experimental data in ground facilities ${ }^{9}$ show that 200 is a reasonably conservative indicator of transition for a 70-deg sphere-cone. Figure 9 shows the forebody $R e_{\theta}$ using LAURA solutions on the $+3 \sigma$ Heat Load trajectory. The $R e_{\theta}>200$ threshold occurs prior to peak heating. If the critical $R e_{\theta}$ level was increased to

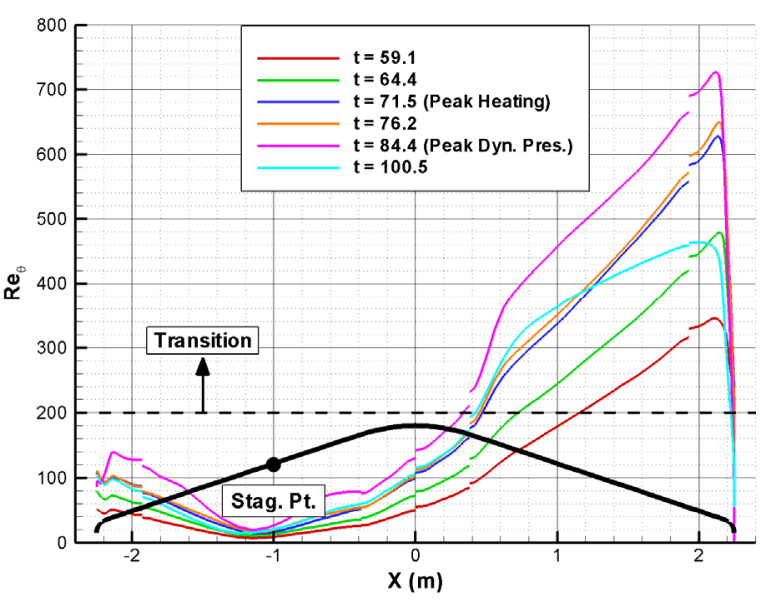

Figure 9. Symmetry Plane Cut of LAURA Heatshield Momentum-Thickness Reynolds Number on the $+3 \sigma$ Heat Load Trajectory

400, turbulent conditions would still exist before peak heating. Rather than designing the TPS for initially laminar conditions and at some time transitioning, the entire heat pulse is specified to be turbulent in the CFD analysis. Turbulent transition prediction is a difficult undertaking and the least TPS risk is believed to occur if a completely turbulent trajectory is assumed. The afterbody environments are still determined using laminar CFD solutions with larger uncertainties to account for turbulent effects. Confidence in turbulence models for an unsteady, separated wake flowfield is not high enough to warrant their use to define the flight heating levels.

Turbulence at the time of peak heating dramatically changes the conditions imposed on the TPS material. Figure 10 displays the effects of turbulence at the peak heating time on the $+3 \sigma$ Heat Flux trajectory. Convective heat flux, surface pressure, and shear stress are shown for a cut of the symmetry plane using the LAURA laminar and Baldwin-Lomax turbulent models. At an angle-ofattack of about $17 \mathrm{deg}$, the stagnation point is on the windside flank $(\mathrm{X}<0)$. Under laminar conditions, the heat flux is highest on the nose cap and windside shoulder, and is not coincident with the stagnation point. The pressure is highest on the windside and decreases as the flow expands around the nose and onto the leeside flank $(\mathrm{X}>0)$. A constant-thickness TPS exposed to laminar conditions would be designed to survive the conditions just to the left of

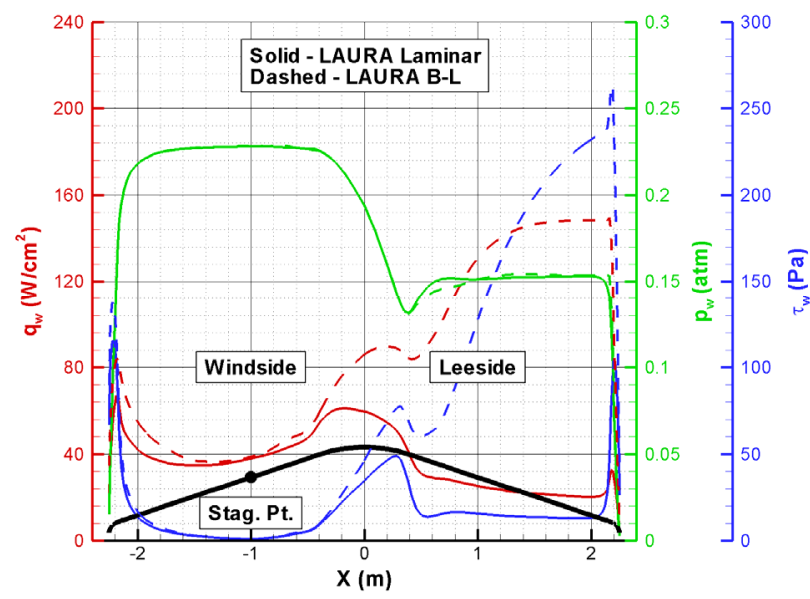

Figure 10. Symmetry Plane Cut of LAURA Laminar and Turbulent Heatshield Heat Flux, Pressure, and Shear Stress on the $+3 \sigma$ Heat Flux Trajectory $(t=72.6 s)$ 
the nose cap, where heating and pressure are high and shear stress is low. The windside shoulder is exposed to high heat flux and shear in laminar conditions, but the area is small and can be treated with a locally augmented TPS.

The situation under turbulent conditions is also shown in Figure 10. The LAURA Baldwin-Lomax model was run with transition forced to begin at the stagnation point to replicate full turbulence. At the stagnation point, the laminar and turbulent conditions are identical. However, as the turbulent boundary layer develops away from the stagnation point, peak heat flux and shear stress move onto the leeside flank and far exceed the laminar levels. Also, heat flux and shear stress reach their maximum at nearly the same location. Turbulent heat flux exceeds peak laminar heating by a factor of 2.5. Shear stress also increases by a similar amount due to turbulence. Thus, under turbulent conditions, the TPS must withstand simultaneously high heat flux and shear stress over a large area, with moderate pressure. Additional testing of SLA-561V is planned specifically to address its response to simultaneously high heat flux and shear since no previous entry capsule is believed to have experienced those conditions. High heating and shear are stressing for an ablative TPS material because the char layer and melted glass may be swept away under shear conditions, thus reducing the efficiency of the ablation process. High pressure could result in unpredictable spallation and diminished material response.

LAURA Baldwin-Lomax predictions are the baseline for defining the heatshield aerothermodynamic environments. As is typically done for Mars aerothermodynamic analysis, multiple CFD codes are used to understand the entry environments. This is especially important for MSL since the prediction of turbulent conditions at peak heating is a first and has necessitated a large experimental program to understand turbulent augmentation effects and TPS response. Only the Viking program seems to have generated turbulent ground-based data $^{34}$ among all Mars aeroheating test programs. In addition, since no flight data exist for turbulent heating at Mars, the CFD turbulence models are not validated for flight conditions. Extensive LAURA/DPLR comparisons to both perfect gas ( air $\left.^{9}, \mathrm{~N}_{2}{ }^{11}\right)$ and high-enthalpy $\left(\mathrm{CO}_{2}{ }^{9,10}\right)$ test data have demonstrated reasonable accuracy of the codes to predict turbulent leeside heating augmentation similar to that shown in Figure 10. Both LAURA and DPLR Baldwin-Lomax solutions have been shown to underpredict turbulent data by about $10-15 \%$ in all facilities. This underprediction is accounted for in the flight environments uncertainties.

Figure 11 shows fully turbulent heat flux, pressure, and shear stress from LAURA (Baldwin-Lomax) and DPLR (Baldwin-Lomax and SST) on the $+3 \sigma$ Heat Flux design trajectory. As expected, pressures are in excellent agreement between the codes. The Baldwin-Lomax results show very similar heating and shear stress distributions, with a rapid leeside augmentation for both properties (Fig. 11a). LAURA predicts an earlier rise in both heating and shear. Maximum values for heat flux and shear stress are within 3\% and 10\% agreement, respectively, which is considered excellent agreement. The conclusion is that no code-to-code uncertainty is needed for the BaldwinLomax model flight predictions for heat flux and shear stress.

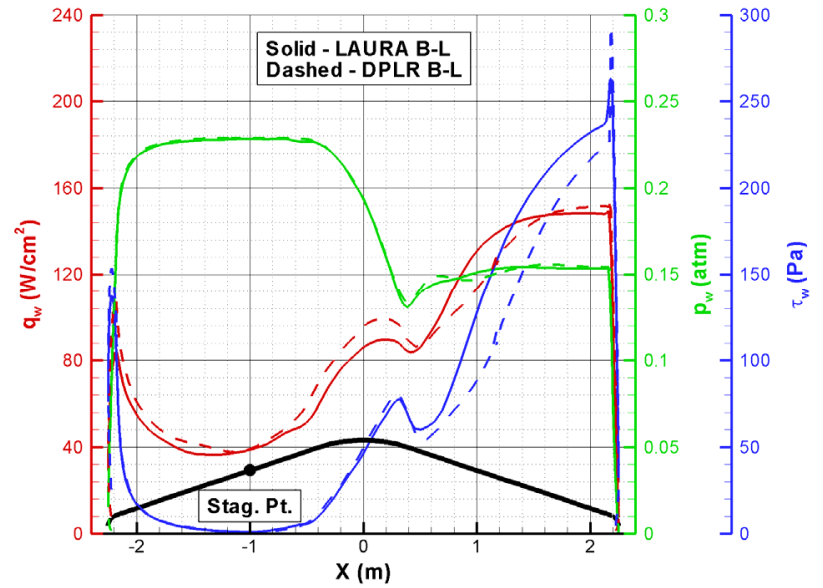

a. LAURA and DPLR Baldwin-Lomax

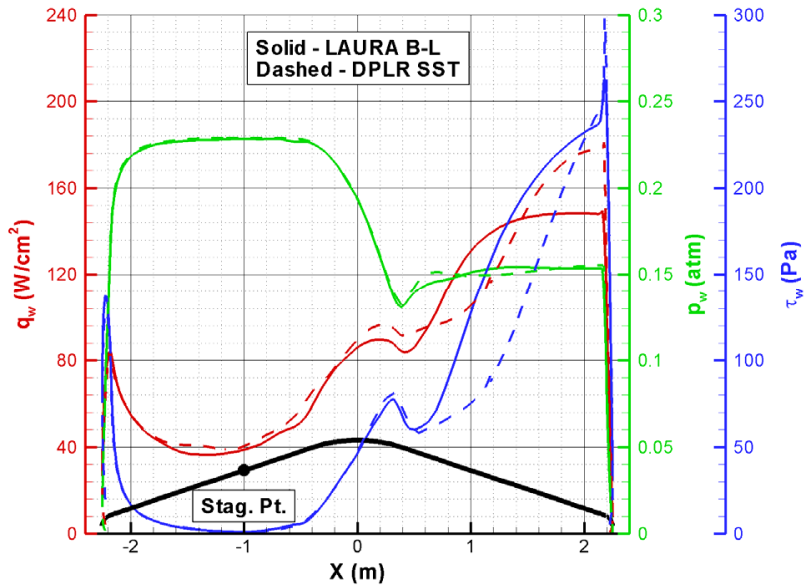

b. LAURA Baldwin-Lomax and DPLR SST

\section{Figure 11. Symmetry Plane Cut of LAURA/DPLR Turbulent Heatshield Heat Flux, Pressure, and Shear Stress on the $+3 \sigma$ Heat Flux Trajectory $(t=72.6 \mathrm{~s}$, No Uncertainties)}


The Baldwin-Lomax model should provide reasonably accurate turbulent heating for attached flows such as blunt forebodies. However, since no data exist to prove this for flight conditions, additional DPLR solutions were been obtained using the SST model. Results are shown in Figure 11b for the LAURA Baldwin-Lomax and DPLR SST predictions. Heat flux, pressure, and shear stress are in excellent agreement on the windside flank. On the leeside, the SST model predicts similar distributions in heating and shear, with a more gradual rise and higher peaks. The maximum SST heat flux and shear stress are about $21 \%$ and $15 \%$ higher, respectively, than the Baldwin-Lomax model predictions. The SST model predicts a slower rise in leeside heat flux and shear stress for unknown reasons. Since the SST model is believed to be a more advanced model, the flight heating uncertainties will account for the differences between the Baldwin-Lomax and SST results.

The heatshield TPS thickness is designed to maintain a peak bondline temperature below $250^{\circ} \mathrm{C}$. The entry trajectory that will result in the highest bondline temperature is the one with the highest integrated heat load. Figure 12a shows LAURA (Baldwin-Lomax) and DPLR (SST) turbulent heat flux predictions along the $+3 \sigma$ Heat Load trajectory. Solutions spanned the heat pulse in order to estimate integrated heat load for TPS design. The DPLR SST heat flux is consistently higher across the entire heat pulse. The integrated effect on total heat load is shown in Figure 12b, where the DPLR SST leeside peak is $15 \%$ higher than the LAURA Baldwin-Lomax peak.

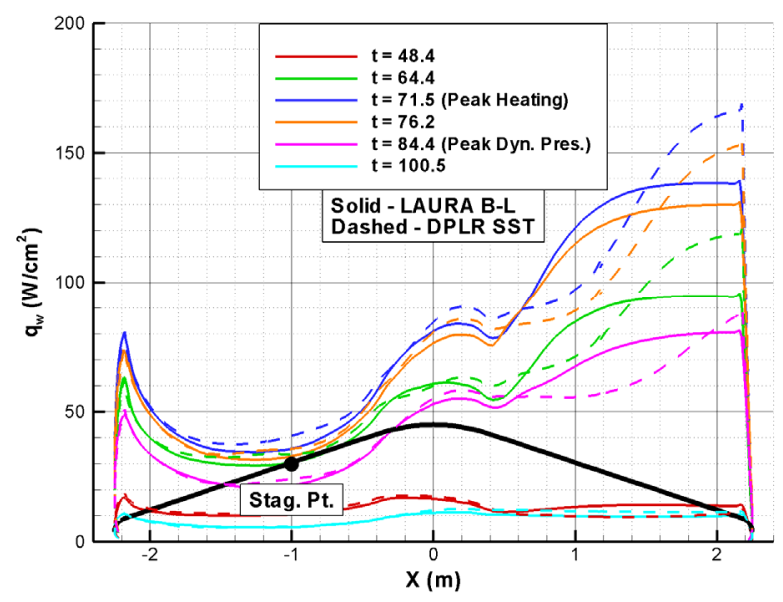

a. Heat Flux

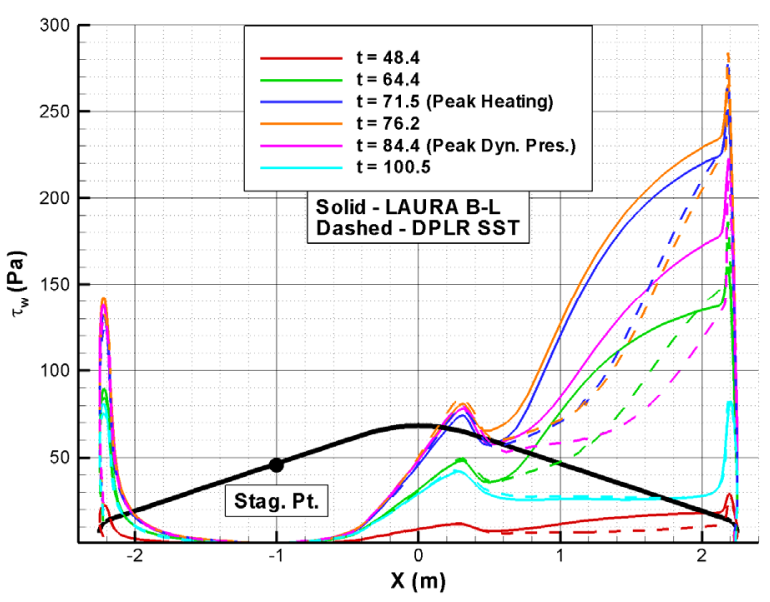

c. Shear Stress

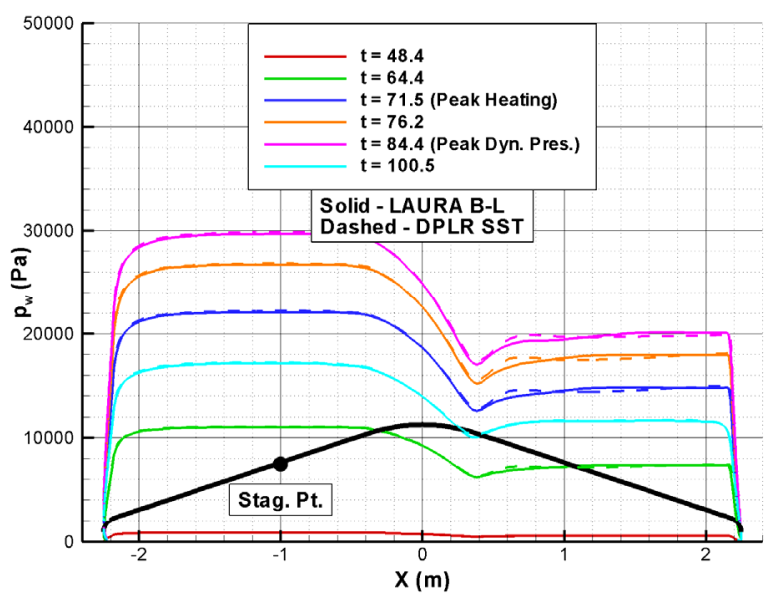

b. Pressure

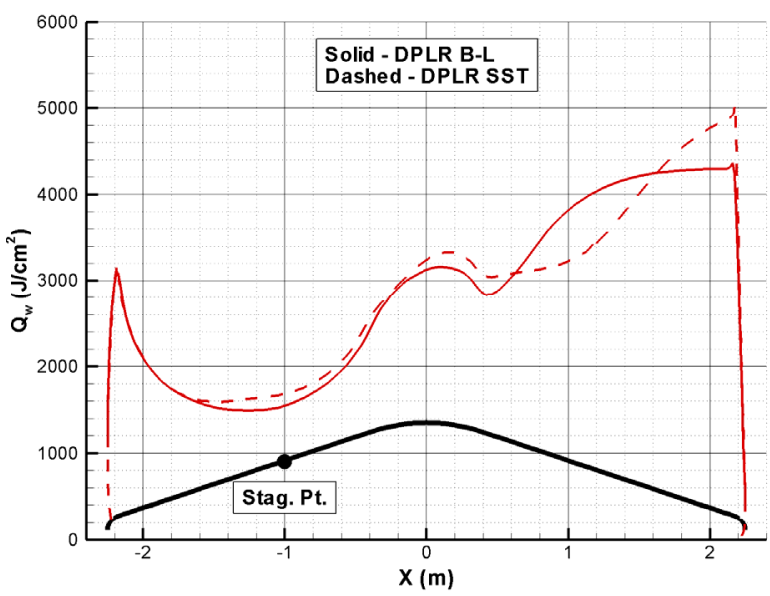

d. Total Heat Load

Figure 12. Symmetry Plane Cut of LAURA/DPLR Turbulent Heatshield Conditions on the $+3 \sigma$ Heat Load Trajectory (No Uncertainties) 
The heatshield design environments must account for uncertainties in the computational tools as well as other variables that affect the surface conditions (trim angle-of-attack, roughness, surface catalysis, etc.). See Reference 35 for an uncertainty analysis of laminar heating at Mars. Most of those sensitivities are determined from experimental data or computational results; a detailed uncertainty analysis is not included here. The uncertainties for heatshield heat flux, pressure, and shear stress are simply applied as multipliers to the LAURA Baldwin-Lomax results:

$$
\begin{aligned}
& q_{\text {Design }}=q_{\text {LAURA,B-L}} \times 1.5 \\
& p_{\text {Design }}=p_{L A U R A, B-L} \times 1.1 \\
& \tau_{\text {Design }}=\tau_{\text {LAURA }, B-L} \times 1.4
\end{aligned}
$$

The design environments at peak heating, with uncertainties included, are shown in Figure 13. On the $+3 \sigma$ Heat Flux trajectory at peak heating, the forebody has two regions that stress the TPS response. First, at the stagnation point, the heat flux and shear stress are low, but the pressure reaches $0.25 \mathrm{~atm}$. Second, on the leeside flank where pressure is $0.17 \mathrm{~atm}$, the heat flux and shear stress reach values of $225 \mathrm{~W} / \mathrm{cm}^{2}$ and $370 \mathrm{~Pa}$, respectively. For comparison, the turbulent heat flux indicator shown earlier, including a 1.5 uncertainty, is $234 \mathrm{~W} / \mathrm{cm}^{2}$. Pressure and shear stress both continue to rise after the peak heating time. Conditions at both regions have been targeted for TPS testing, although all three quantities cannot be obtained simultaneously in the test facilities. The MSL heatshield TPS will be a constant thickness designed to withstand a total heat load of $6500 \mathrm{~J} / \mathrm{cm}^{2}$ (Fig. 13b).

Figure 14 illustrates the envelope of conditions from all heatshield grid points in the LAURA Baldwin-Lomax solutions. These plots identify the extrema for simultaneous heating/pressure/shear conditions that the heatshield TPS must withstand at any given time. Peak heat flux and shear are shown to occur at nearly the same time and location as heat flux, whereas peak pressure occurs later in the trajectory and at a different heatshield location.
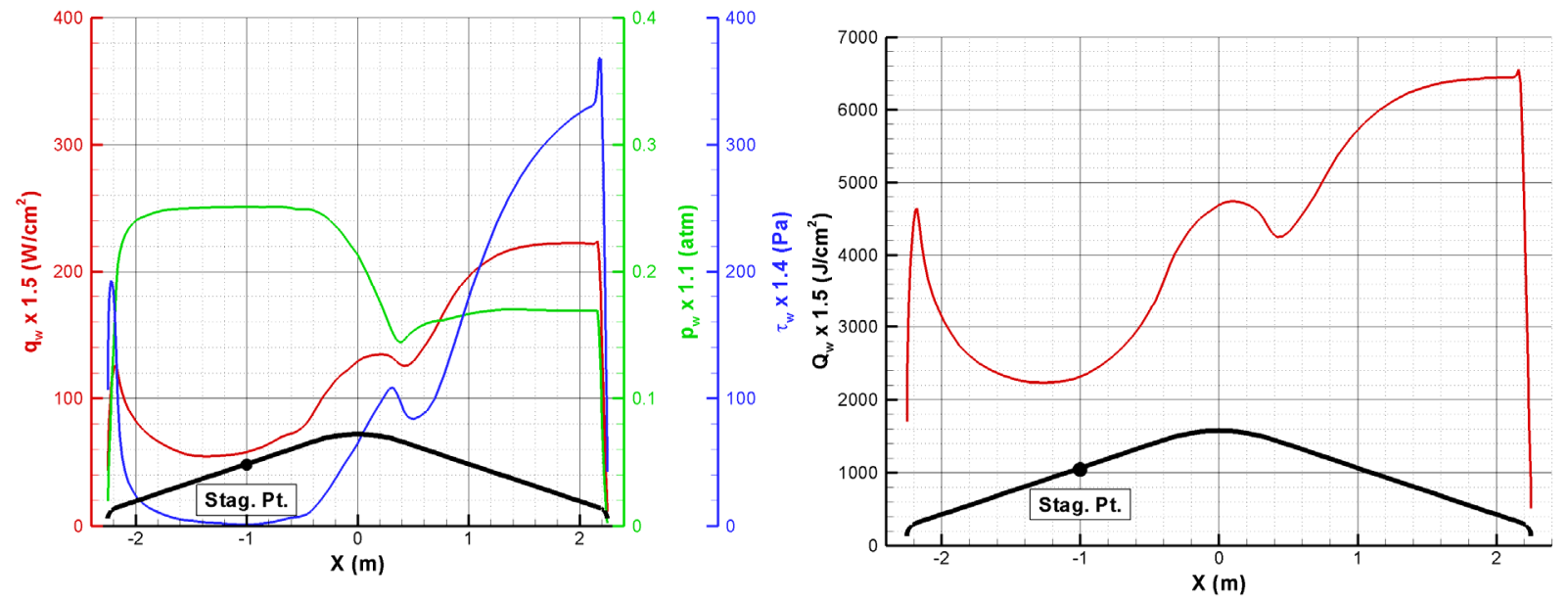

\section{a. Heat Flux, Pressure, and Shear Stress at Peak} Heating on the $+3 \sigma$ Heat Flux Trajectory $(t=72.6 s)$

b. Total Heat Load on the $+3 \sigma$ Heat Load Trajectory

Figure 13. Heatshield Design Environments (Uncertainties Included)

\section{Backshell and Parachute Cover Environments}

The backshell heating levels for past Mars missions have been a small percentage of the heatshield levels (see Ref. 36 as an example). LAURA and DPLR solutions have been compared to flight data from Viking Lander 1, but the results were inconclusive ${ }^{37}$. The heating has been low enough to use a spray-on version of the SLA-561 material, which is less capable than the honeycomb-packed version. Several characteristics of the MSL entry will 


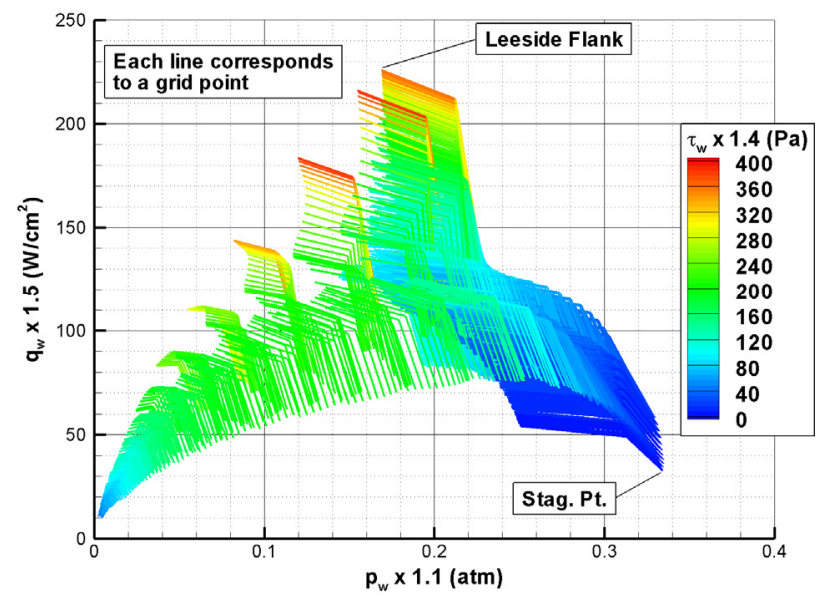

a. $+3 \sigma$ Heat Flux Trajectory

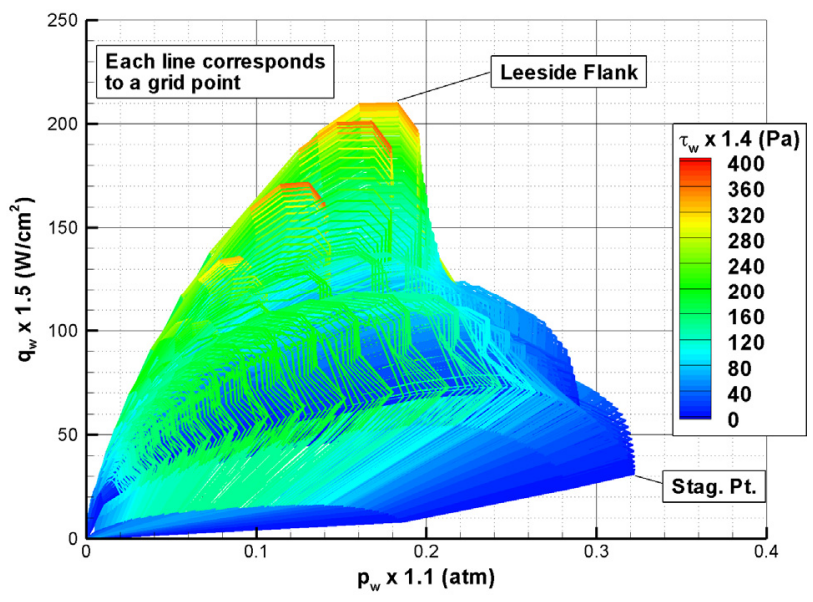

b. $+3 \sigma$ Heat Load Trajectory

Figure 14. Heatshield Design Heat Flux, Pressure, and Shear Stress (Uncertainties Included)

lead to heating levels that require the use of SLA-561V on the backshell as well. First, the MSL ballistic coefficient leads to augmented heating in much the same way it affects heatshield turbulent transition and heating augmentation. Second, the MSL angle-of-attack is higher than all past missions, which exposes the backshell to more energetic attached flow. Finally, the MSL capsule will use RCS jets during entry to perform coordinated banking maneuvers to achieve precision landing. The current RCS configuration creates jet plume interference effects that dramatically increase transient localized heating levels on the backshell and parachute cover. The large uncertainties in predicting massively separated, unsteady, and possibly turbulent wake flowfields also contribute to design heating levels that require a more capable backshell TPS material.

\section{Environments Without RCS Thrusters}

The backshell and parachute cover conditions were first estimated without RCS thrusters firing. The heating design trajectories that were used to define the heatshield conditions were also used to predict the backshell and parachute cover environments. Both LAURA and DPLR laminar solutions were obtained on the design trajectories, with uncertainties applied to the LAURA results. The uncertainties include an estimate for turbulent augmentation effects given the low confidence in using turbulent Navier-Stokes solutions for unsteady wake flowfields.

Figure 15 shows LAURA and DPLR laminar backshell heat flux, pressure, and shear stress at peak freestream dynamic pressure on the $+3 \sigma$ Heat Flux trajectory. The backshell and parachute cover heating levels reach their peaks at this time on the trajectory. At about 17 deg angle-of-attack, the flow remains attached for most of the backshell "windside" $(\mathrm{X}<0)$. LAURA and DPLR both predict flow separation on the second backshell cone and reattachment on the parachute cover. DPLR predicts more severe conditions than does LAURA immediately after the shoulder, for unknown reasons. LAURA predicts separation further downstream, but the peak conditions on the corners are very similar between the codes. The CFD solutions were run steady-state, but the conditions in the separated flow region are unsteady. Fortunately, the surface conditions in the separated flow should be much less severe. Large uncertainties must be included to account for the difficulty in predicting an unsteady and possibly turbulent wake. The backshell TPS will have a constant thickness, so it will be sized to the worst-case surface conditions at the breakpoints. Based on the current computational results, small code-to-code differences at the backshell corner and parachute cover edge may not need special attention in the uncertainties. 


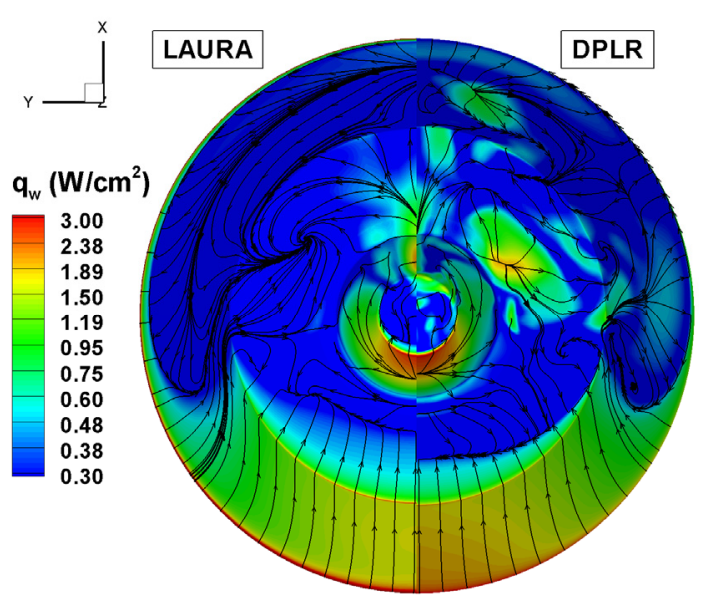

a. Heat Flux

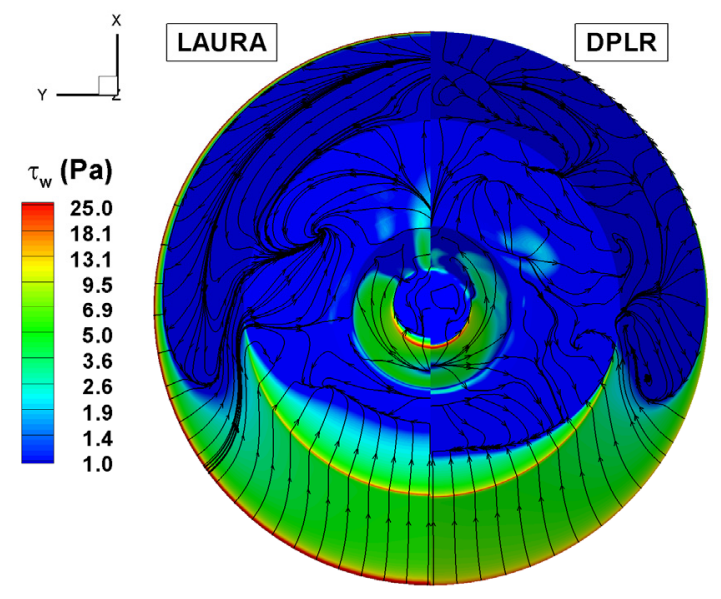

c. Shear Stress

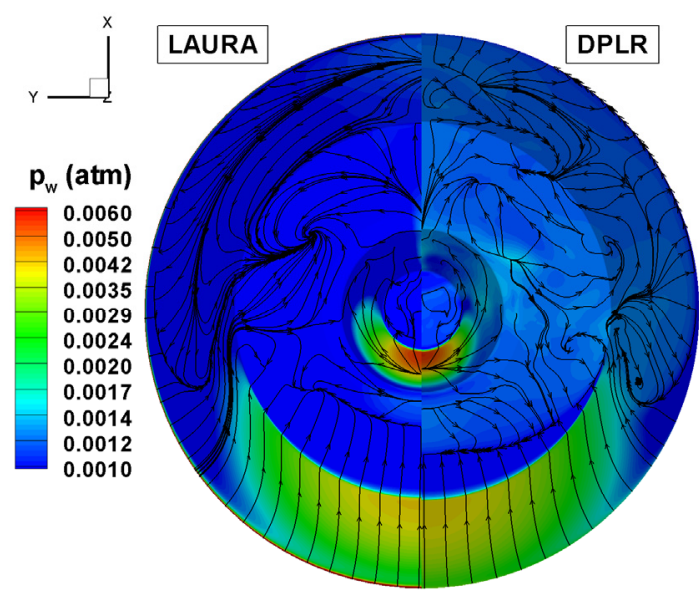

\section{b. Pressure}

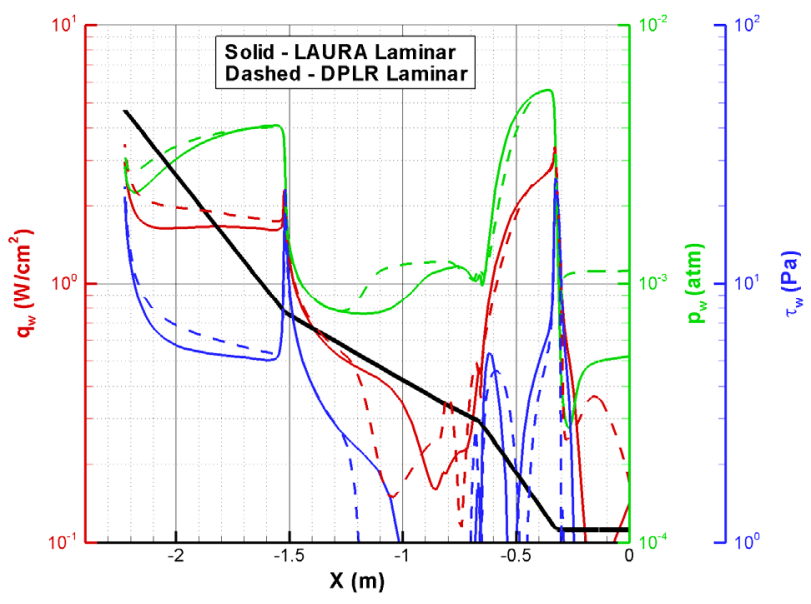

c. Windside Symmetry Plane Cut

Figure 15. LAURA/DPLR Laminar Backshell and Parachute Cover Conditions on the $+3 \sigma$ Heat Flux Trajectory $(t=85.3 \mathrm{~s}$, No Uncertainties)

Additional solutions were run along the entire heat pulse for the $+3 \sigma$ Heat Load trajectory (Fig. 16). DPLR consistently predicts higher heat flux than LAURA on most of the windside backshell, which is consistent with the previous results. Better agreement in the attached flow heating was expected, but the reasons for this discrepancy are unknown. Nevertheless, the peak conditions at the breakpoints are similar. After flow reattachment on the parachute cover, the code-to-code differences are small at the cover edge. Integrated total heat load from DPLR is higher, especially on the first backshell cone. The final flight uncertainties will account for the code-to-code differences, which are currently small at the breakpoints.

The backshell and parachute cover design environments are based on the LAURA laminar solutions. The TPS materials will be designed with a constant thickness, so the worst-case conditions are used for design purposes. A turbulent transition estimate analogous to the heatshield results has not been performed for the backshell. Confidence is low in using available turbulence models, which are generally designed for attached flows, to accurately capture the physics of unsteady wake flowfields. An additional scaling factor is applied to the laminar results to estimate the effects of turbulence on heat flux and shear stress. The design heating, pressure, and shear stress for the backshell without RCS thruster effects are as follows:

$$
q_{\text {Design }}=q_{\text {LAURA,Lam }} \times 1.5 \times 2
$$




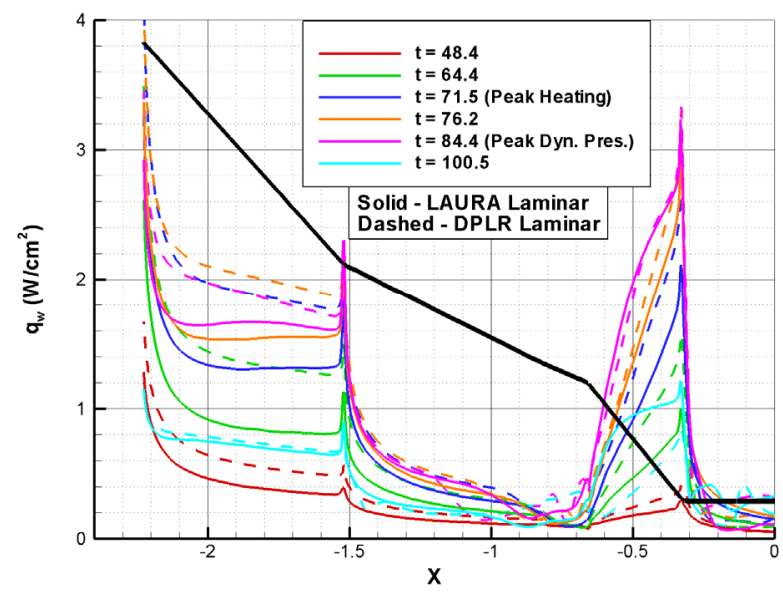

a. Heat Flux

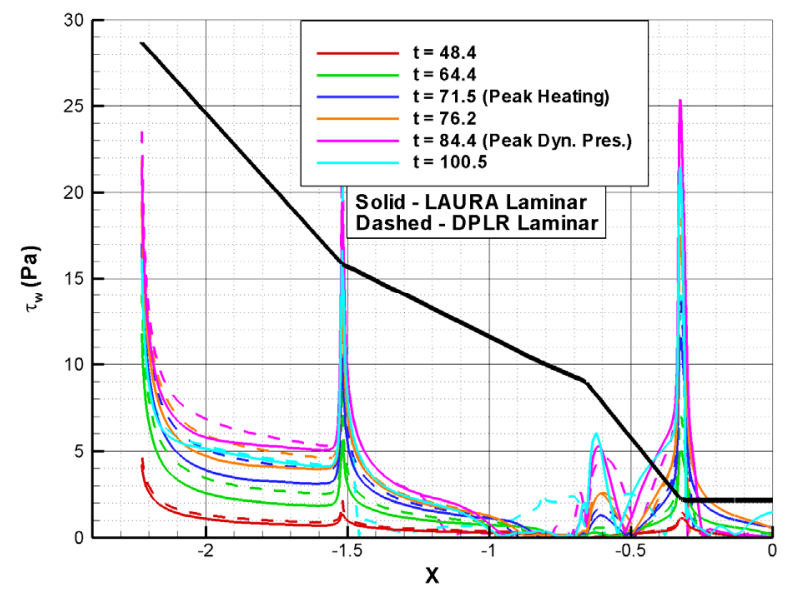

c. Shear Stress

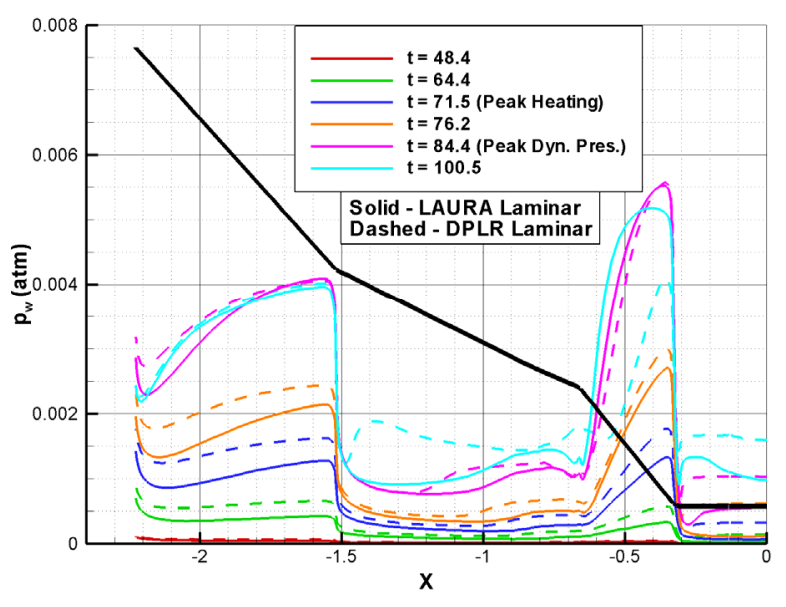

d. Pressure

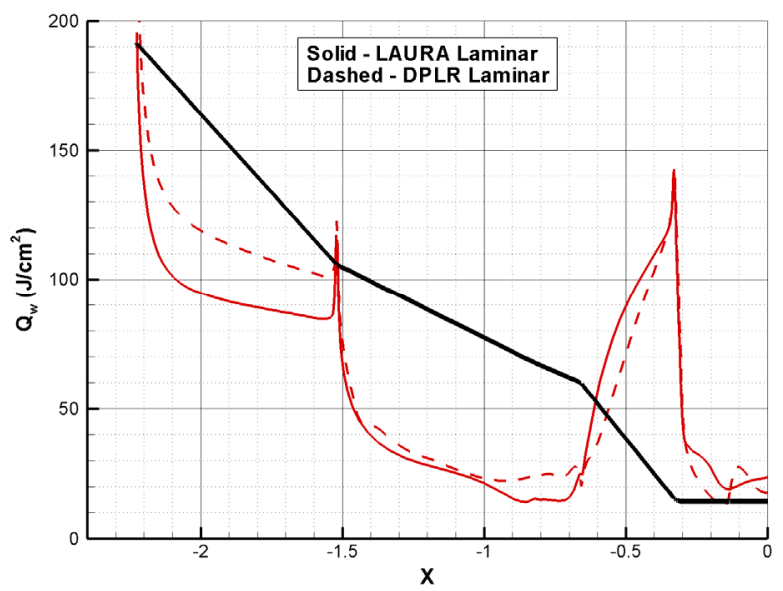

d. Total Heat Load

Figure 16. Windside Symmetry Plane Cut of LAURA/DPLR Laminar Conditions on the $+3 \sigma$ Heat Load Trajectory (No Uncertainties)

$$
\begin{gathered}
p_{\text {Design }}=p_{\text {LAURA,Lam }} \times 1.5 \\
\tau_{\text {Design }}=\tau_{\text {LAURA,Lam }} \times 1.4 \times 2
\end{gathered}
$$

The factor of 2 in Equations 9 and 11 are an estimate of turbulent effects. An additional margin may be necessary for some parts of the backshell where code-to-code discrepancies are larger. However, the conditions from LAURA and DPLR at the breakpoints are considered close enough to not require additional margin. The cumulative uncertainties are much larger than those for the heatshield due to the difficulty in predicting unsteady wake flowfields with steady-state Navier-Stokes flow solvers.

The windside backshell and parachute design environments without RCS thruster firings are summarized in Figure 17. At the time of peak dynamic pressure and including uncertainties from Equations 9-11, the conditions on the windside backshell hip are $7 \mathrm{~W} / \mathrm{cm}^{2}$ for heat flux, $0.006 \mathrm{~atm}$ for pressure, and $55 \mathrm{~Pa}$ for shear stress. Integrated heat load at the same location is $350 \mathrm{~J} / \mathrm{cm}^{2}$. The conditions immediately after the shoulder $(\mathrm{X}=-2.25 \mathrm{~m}$ in Fig. 17) are more severe, but a thicker TPS will be used at that location. Flow reattachment on the parachute cover rear edge is predicted to cause more severe environments than those on the backshell hip. Parachute cover design 
environments at peak dynamic pressure on the $+3 \sigma$ Heat Flux trajectory are $10 \mathrm{~W} / \mathrm{cm}^{2}$ for heat flux, 0.008 atm for pressure, and $70 \mathrm{~Pa}$ for shear stress. Design integrated heat load on the $+3 \sigma$ Heat Load trajectory is $430 \mathrm{~J} / \mathrm{cm}^{2}$.

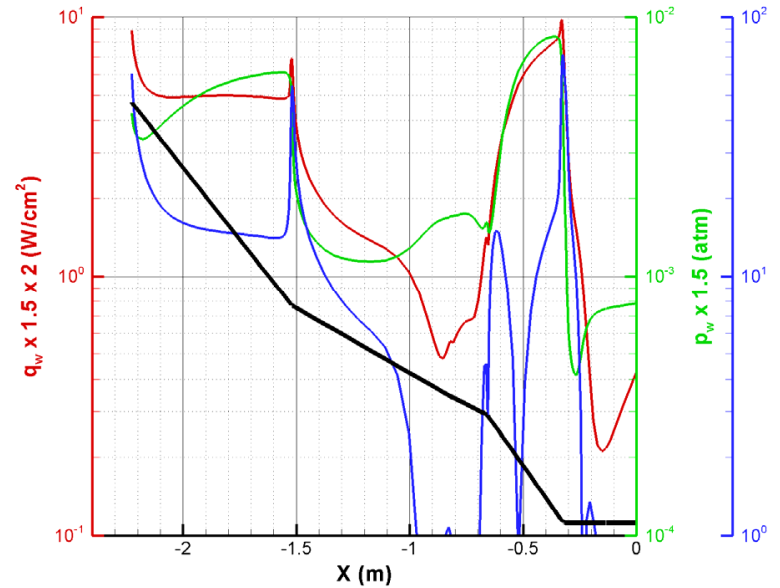

a. Heat Flux, Pressure, and Shear Stress on the $+3 \sigma$ Heat Flux Trajectory $(\mathrm{t}=\mathbf{8 5 . 3} \mathrm{s})$

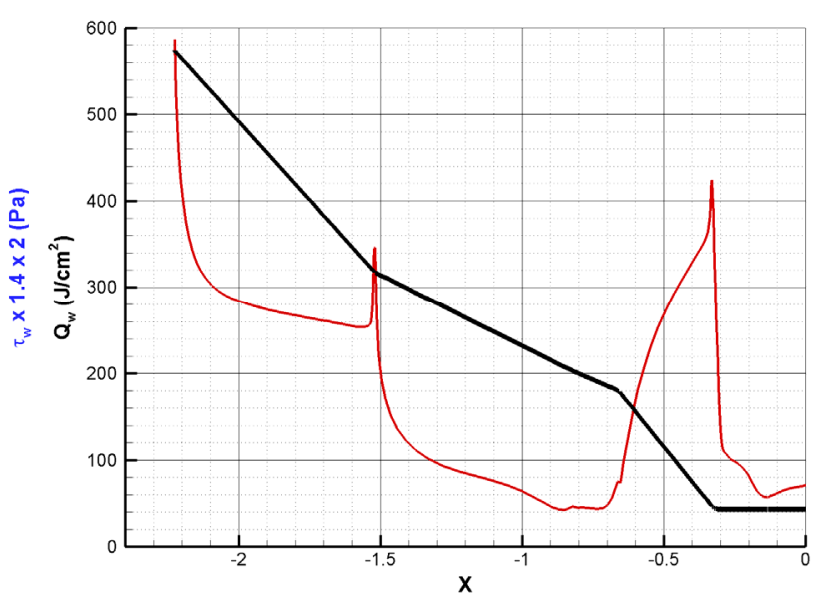

b. Total Heat Load on the $+3 \sigma$ Heat Flux Trajectory

Figure 17. Windside Symmetry Plane Cut of Backshell and Parachute Cover Design Environments (No RCS Thruster Effects, Uncertainties Included)

Figures 18 and 19 show the envelope of design heat flux, pressure, and shear stress for the backshell and parachute cover on both heating trajectories. Again, as with the heatshield, the peak values occur at different times along the trajectory and at different locations. The peak values on the $+3 \sigma$ Heat Flux trajectory regardless of timing or location for the backshell are a heat flux of $7 \mathrm{~W} / \mathrm{cm}^{2}$, a pressure of $0.006 \mathrm{~atm}$, and a shear stress of $55 \mathrm{~Pa}$. Peak values on the parachute cover are a heat flux of $10 \mathrm{~W} / \mathrm{cm}^{2}$, a pressure of $0.0085 \mathrm{~atm}$, and a shear stress of $72 \mathrm{~Pa}$.

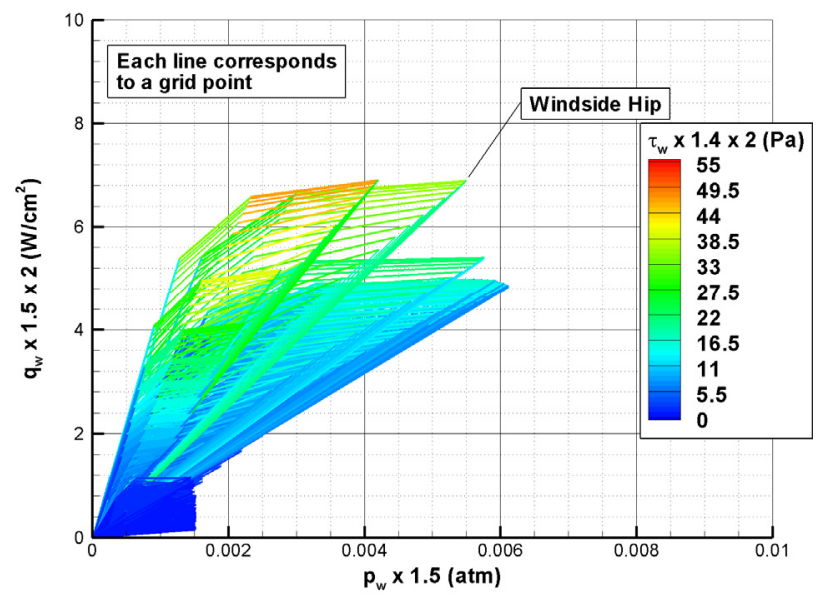

a. $+3 \sigma$ Heat Flux Trajectory

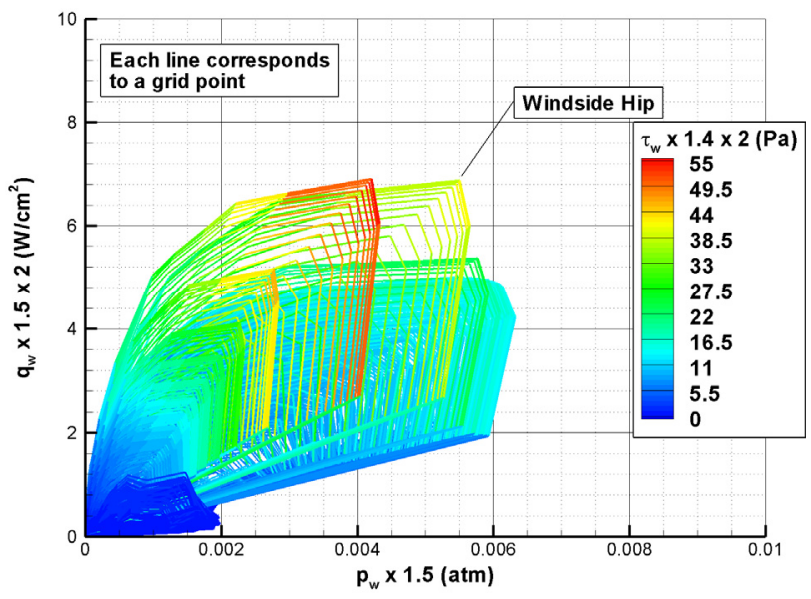

b. $+3 \sigma$ Heat Load Trajectory

Figure 18. Backshell Design Heat Flux, Pressure, and Shear Stress (No RCS Thruster Effects, Uncertainties Included) 


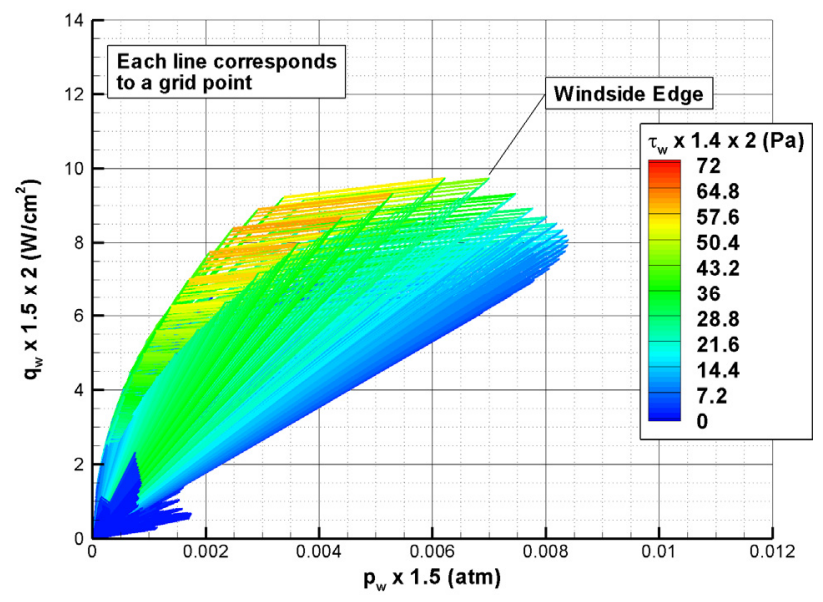

a. $+3 \sigma$ Heat Flux Trajectory

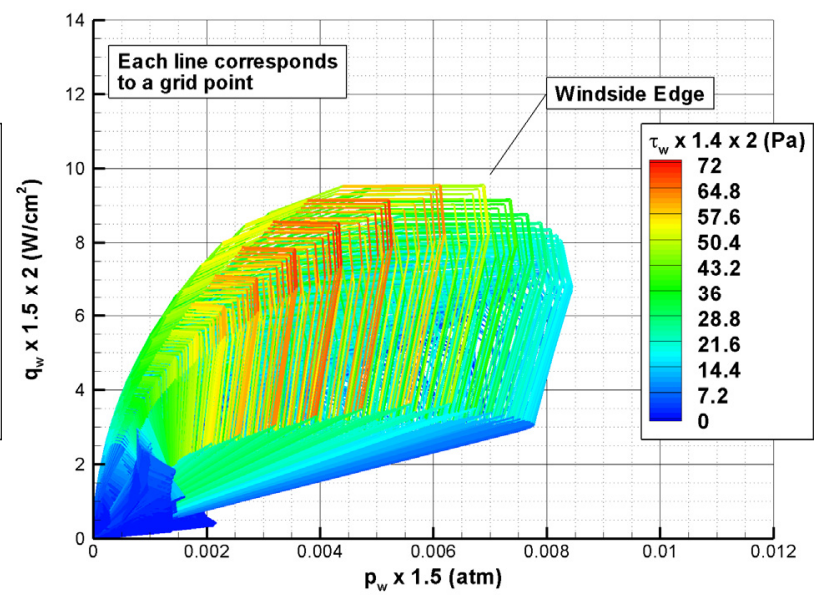

b. $+3 \sigma$ Heat Load Trajectory

Figure 19. Parachute Cover Design Heat Flux, Pressure, and Shear Stress (No RCS Thruster Effects, Uncertainties Included)

\section{RCS Thruster Effects}

The backshell conditions without RCS thruster firings, including margins from Equations 9-11, are at or near the performance limits of the spray-on version of SLA-561 due to high angle-of-attack and large ballistic coefficient. Additional CFD solutions were obtained to estimate RCS plume interference effects on surface conditions. LAURA and DPLR laminar flowfield solutions were run with a single windside thruster firing at peak freestream dynamic pressure on the $+3 \sigma$ Heat Flux trajectory. Non-reacting ammonia $\left(\mathrm{NH}_{3}\right)$ was used as the thruster gas in both codes. In reality, the plume exhaust from hydrazine combustion may react with the surrounding $\mathrm{CO}_{2}-\mathrm{N}_{2}$ gas.

Figure 20 shows the plume boundary from LAURA with a windside RCS thruster firing. The windside RCS nozzles location and pointing direction result in the interaction of supersonic plume and wake flowfields. The codes were run in steady-state mode rather than time-accurate and the results are shown for a given time. However, the solutions never truly reached a steady state as the RCS-induced conditions moved around and changed magnitude during the solution process. The computed plumes were allowed to fully develop using maximum thrust chamber conditions. During flight, the RCS thruster firing will be a transient event that causes the plume to appear and disappear over a full cycle. Thus, the interference structures and augmented surface conditions will be an unsteady event. Unsteady CFD computations have been obtained yet.

Figure 21 shows the result of the exhaust plume colliding with the oncoming supersonic flowfield. Heat flux and pressure contours with and without the RCS thruster modeled are shown for the LAURA solutions. The plume interaction creates a horseshoe-shaped shock with locally high heating and pressure at the separation location. The uncertainties in the magnitude and location of the locally severe conditions are high given the difficulty in predicting the interaction of plume and wake flowfields. It is this high heat flux that caused the decision to use SLA-561V on the backshell rather than the spray-on version.

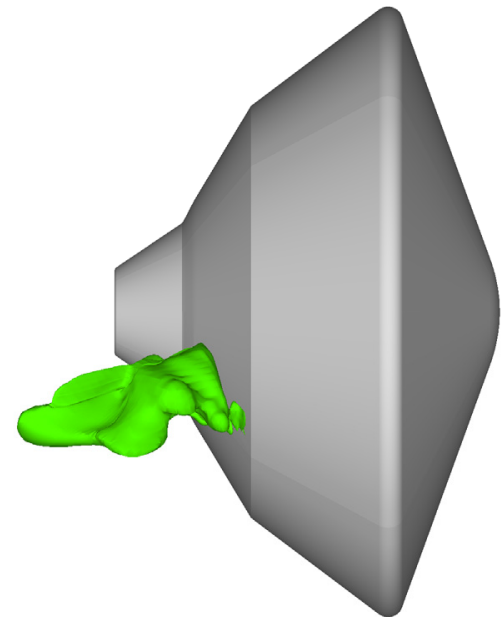

Figure 20. LAURA Plume Boundary $\left(0.6 \mathrm{NH}_{3}\right.$ Mass Fraction) of a Windside RCS Thruster on the $+3 \sigma$ Heat Flux Trajectory $(t=85.3 \mathrm{~s})$ 


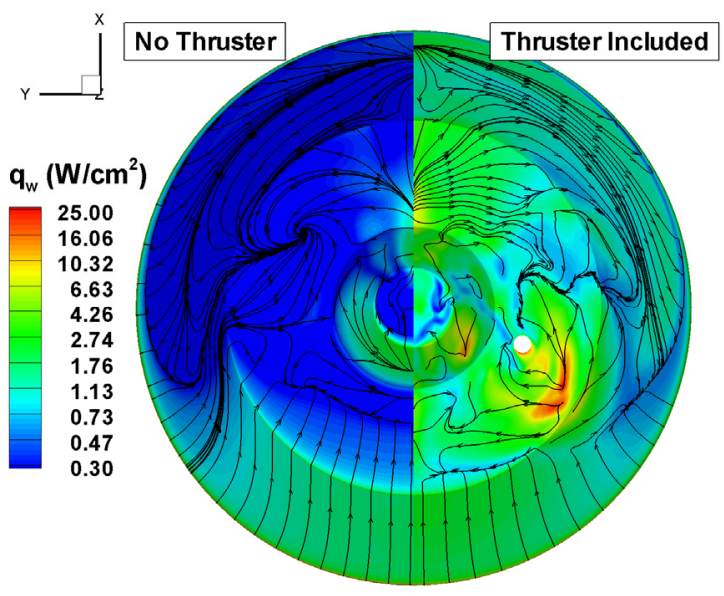

a. Heat Flux

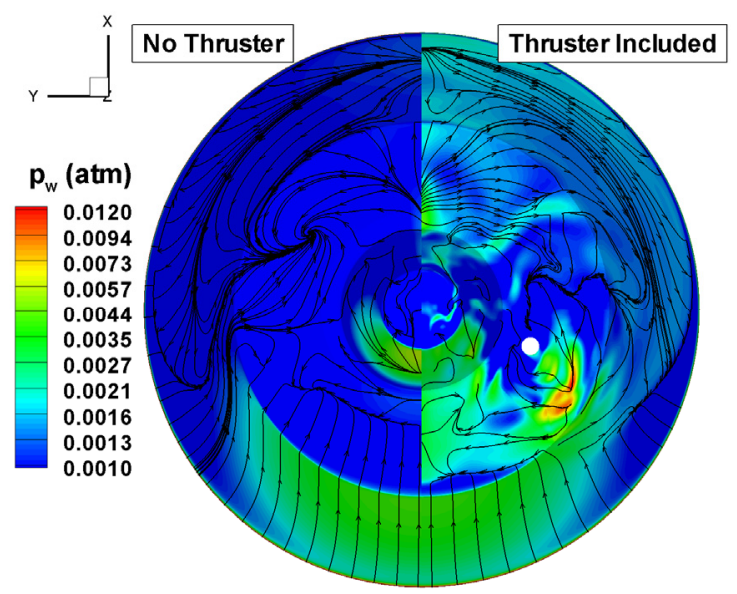

b. Pressure

Figure 21. LAURA Backshell and Parachute Conditions with and without a Windside RCS Thruster Firing on the $+3 \sigma$ Heat Flux Trajectory $(t=85.3 \mathrm{~s}$, No Uncertainties $)$

The backshell and parachute cover design RCS-induced design environments are obtained by applying the same uncertainties from Equations 9-11 to the conditions in Figure 21. Both CFD codes predict similar patterns of locally-augmented surface heat flux and pressure, as well as impingement of the shock on the parachute cover. The agreement between the two codes is considered excellent given the large uncertainties in such calculations and relative immaturity of using these codes for plume interaction analyses. The design conditions only apply if the RCS thrusters are used at peak dynamic pressure. Of course, RCS usage at other times would also create more severe environments than the baseline. The backshell conditions at peak dynamic pressure are a heat flux of are $72-$ $76 \mathrm{~W} / \mathrm{cm}^{2}$ (LAURA higher), a pressure of 0.015-0.018 atm (LAURA higher), and a shear stress of $25 \mathrm{~Pa}$ (not shown). The parachute cover design environments with RCS effects included are $27-38 \mathrm{~W} / \mathrm{cm}^{2}$ for heat flux (LAURA higher), a pressure of 0.005-0.008 atm (LAURA higher), and a shear stress of 20 Pa (not shown). The RCS effects on total heat load will depend on the timing and duration of the thruster firings during atmospheric entry. The aerothermodynamic environments will require updating for any change to the entry system that affects the aeroshell geometry, heating design trajectories, or RCS configuration.

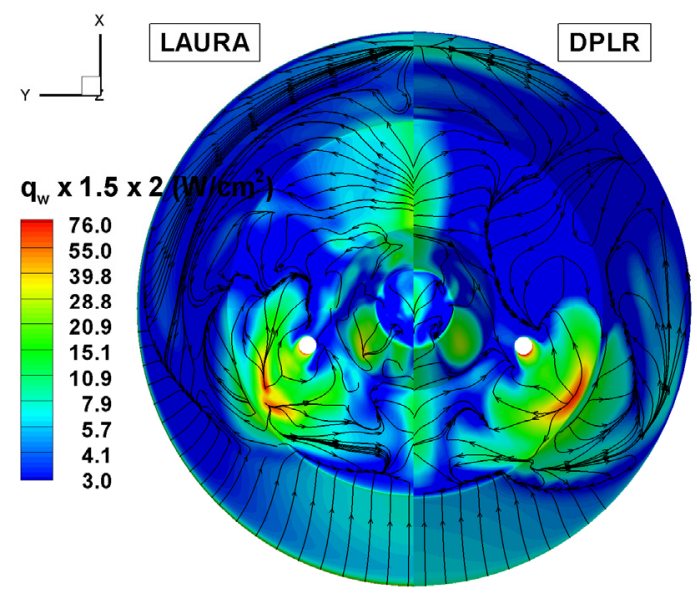

a. Heat Flux

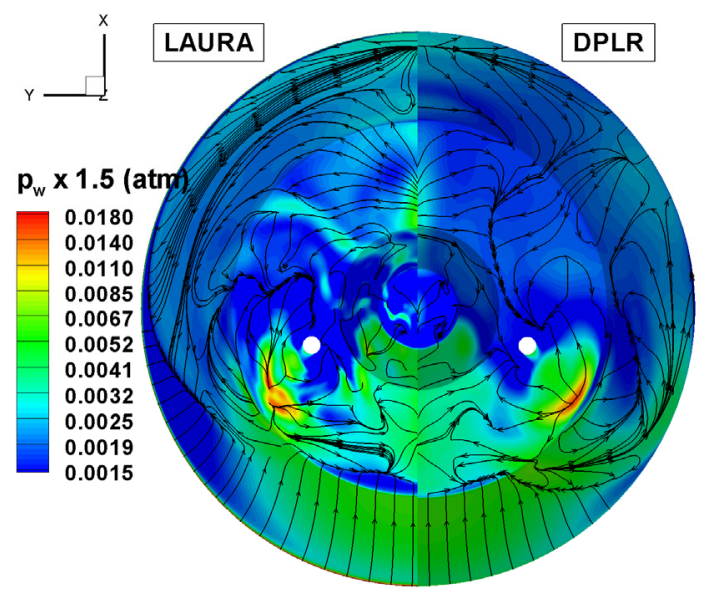

b. Pressure

Figure 22. LAURA/DPLR Backshell and Parachute Cover Design Conditions with a Windside RCS Thruster Firing on the $+3 \sigma$ Heat Flux Trajectory $(t=85.3$ s, Uncertainties Included $)$ 


\section{Summary and Conclusions}

The Mars Science Laboratory entry capsule is predicted to experience unprecedented aerothermodynamic environments (heat flux, pressure, and shear stress) based on Navier-Stokes flowfield predictions on heating design entry trajectories. A high ballistic coefficient, non-zero angle-of-attack, and large aeroshell size all contribute to heatshield turbulent transition prior to the time of peak heating, a first for Mars entry capsules. The same honeycomb-packed SLA-561V thermal protection system (TPS) material that has been used for less severe conditions in the past will also be used for the MSL heatshield. A momentum-thickness Reynolds number criterion of 200 is used to predict transition and is exceeded early in the design trajectory. The computational predictions have necessitated a large experimental program to quantify turbulent augmentation effects for blunt bodies, for which there are few historical data. Turbulence significantly increases heating and shear stress on the heatshield compared to laminar conditions. Moreover, both heating and shear reach their peaks at nearly the same heatshield location and time, which stresses the TPS and has required extensive material response testing under relevant conditions.

Fully-turbulent heatshield computations were run using the LAURA and DPLR Navier-Stokes flow solvers. Solutions were obtained on the $+3 \sigma$ Heat Flux and Heat Load trajectories to determine peak heat flux, pressure, shear stress, and total heat load. Excellent agreement is shown between the two codes' Baldwin-Lomax results on the heatshield. The DPLR Shear Stress Transport (SST) model predicts $21 \%$ higher heat flux and $15 \%$ higher shear stress than do the LAURA Baldwin-Lomax solutions. The code-to-code discrepancy is included in the heatshield environments uncertainties, which also account for other modeling effects. Peak design conditions including uncertainties are $225 \mathrm{~W} / \mathrm{cm}^{2}$ for heat flux (1.5 uncertainty), $0.32 \mathrm{~atm}$ for stagnation pressure (1.1 uncertainty), 400 Pa for shear stress (1.4 uncertainty), and $6500 \mathrm{~J} / \mathrm{cm}^{2}$ for total heat load (1.5 uncertainty). Peak heating and shear stress occur nearly simultaneously in time and at the same heatshield location. Peak pressure occurs later in the trajectory and is lower where heating and shear are highest.

The MSL backshell and parachute cover environments are also expected to be more severe than past experience due to attached flow on portions of the afterbody and plume interference effects from the reaction control system (RCS). A high ballistic coefficient and the possibility of turbulence in the wake also lead to more severe conditions. Neglecting the effects of RCS thrusters, the design heat flux reaches $7-10 \mathrm{~W} / \mathrm{cm}^{2}$ (uncertainty factor of 3 ) on the backshell and parachute cover. Both LAURA and DPLR solutions were obtained with the RCS thrusters modeled as a single hole with supersonic exit conditions. Both codes predict a plume interference that is manifested as a horseshoe-shaped shock that augments backshell and parachute cover conditions by an order of magnitude. If a windside RCS jet is fired at peak dynamic pressure, the codes predict a backshell design heat flux of $72-76 \mathrm{~W} / \mathrm{cm}^{2}$ and pressure of 0.015-0.018 atm upstream of the thruster location. Both codes also predict that the interference shock will impinge the parachute cover and augment surface conditions. During a thruster firing at peak dynamic pressure, design heat flux and pressure on the parachute cover are $27-38 \mathrm{~W} / \mathrm{cm}^{2}$ and $0.005-0.008 \mathrm{~atm}$, respectively. The RCS effects have prompted the decision to also use honeycomb-packed SLA-561V on the backshell rather than a less capable spray-on version. Updates to the hardware design environments will occur as changes to the aeroshell, RCS configuration, design entry trajectories, and uncertainties are updated. 


\section{References}

${ }^{1}$ Lockwood, M. K., "Introduction: Mars Science Laboratory: The Next Generation of Mars Landers," Journal of Spacecraft and Rockets, Vol. 43, No. 2, March-April, 2006, p. 257.

${ }^{2}$ Lockwood, M. K., Powell, R. W., Sutton, K., Prabhu, R. K., Graves, C. A., Epp, C. D., and Carman, G. L, "Entry Vehicle Configurations and Performance for the Mars Smart Lander," Journal of Spacecraft and Rockets, Vol. 43, No. 2, March-April, 2006, pp. 258-269.

${ }^{3}$ Edquist, K. T., Liechty, D. S., Hollis, B. R., Alter, S. J., and Loomis, M. P., “Aeroheating Environments for a Mars Smart Lander," Journal of Spacecraft and Rockets, Vol. 43, No. 2, March-April, 2006, pp. 330-339.

${ }^{4}$ Edquist, K. T., and Alter, S. J., "Computational Aeroheating Predictions for Mars Lander Configurations," AIAA Paper 2003-3639, AIAA Thermophysics Conference, Orlando, FL, June 2003.

5 Edquist, K. T., "Afterbody Heating Predictions for a Mars Science Laboratory Entry Vehicle," AIAA Paper 2005-4817, AIAA Thermophysics Conference, Toronto, Ontario, Canada, June 2005.

${ }^{6}$ Liechty, D. S. and Hollis, B. R., "Heat Shield Cavity Parametric Experimental Aeroheating for a Proposed Mars Smart Lander Aeroshell," AIAA Paper 2002-2746, AIAA Fluid Dynamics Conference and Exhibit, St. Louis, MO, June 2002.

7 Hollis, B. R. and Liechty, D. S., "Boundary Layer Transition Correlations and Aeroheating Predictions for Mars Smart Lander," AIAA Paper 2002-2745, AIAA Fluid Dynamics Conference and Exhibit, St. Louis, MO, June 2002.

${ }^{8}$ Liechty, D. S. and Hollis, B. R., "Mars Science Laboratory Experimental Aerothermodynamics with Effects of Cavities and Control Surfaces," Journal of Spacecraft and Rockets, Vol. 43, No. 2, March-April, 2006, pp. 340-353.

${ }^{9}$ Hollis, B. R., Liechty, D. S., Wright, M. J., Holden, M. S., Wadhams, T. P., MacLean, M., and Dyakonov, A., "Transition Onset and Turbulent Heating Measurements for the Mars Science Laboratory Entry Vehicle," AIAA Paper 2005-1437, AIAA Aerospace Sciences Meeting and Exhibit, Reno, Nevada, January 2005.

${ }^{10}$ Wright, M. J., Olejniczak, J., Brown, J. L., Hornung, H. G., and Edquist, K. T.," Computational Modeling of T5 Laminar and Turbulent Heating Data on Blunt Cones, Part 2: Mars Applications," AIAA Paper 2005-0177, AIAA Aerospace Sciences Meeting and Exhibit, Reno, NV, January 2005.

${ }^{11}$ Hollis, B. R. and Collier, A. S., "Turbulent Aeroheating Testing of Mars Science Laboratory Entry Vehicle in Perfect-Gas Nitrogen," AIAA Paper 2007-1208, AIAA Aerospace Sciences Meeting and Exhibit, Reno, NV, January 2007.

${ }^{12}$ Wright, M. J., Milos, F. S., and Tran, P., "Survey of Afterbody Aeroheating Flight Data for Planetary Probe Thermal Protection System Design," Journal of Spacecraft and Rockets, Vol. 43, No. 5, 2006, pp. 929-943.

${ }^{13}$ Sutton, K. and Graves, R. A., "A General Stagnation-Point Convective-Heating Equation for Arbitrary Gas Mixtures," NASA TR R-376, November 1971.

${ }^{14}$ Nielsen, H. B., "UCMINF - An Algorithm for Unconstrained, Nonlinear Optimization,” Technical Report IMM-REP-200019, Technical University of Denmark, DK-2800 Lyngby, Denmark, December 2000.

${ }^{15}$ Olynick, D., Loomis, M., Chen, Y.-K., Venkatapathy, E., and Allen, G., "New TPS Design Strategies for Planetary Entry Vehicle Design," AIAA Paper AIAA 99-0348, AIAA Aerospace Sciences Meeting and Exhibit, Reno, NV, January 1999.

${ }^{16}$ Willcockson, W. H., "Mars Pathfinder Heatshield Design and Flight Experience," Journal of Spacecraft and Rockets, Vol. 36, No. 3, May-June 1999.

${ }^{17}$ Cheatwood, F. M. and Gnoffo, P. A., "User's Manual for the Langley Aerothermodynamic Upwind Algorithm (LAURA)," NASA TM-4674, April 1996.

${ }^{18}$ Papadopoulos, P., Prahbu, D., Olynick, D., Chen, Y. K., and Cheatwood, F. M., "CFD Code Validation and Comparisons for Mars Entry Simulations," AIAA Paper 98-0272, AIAA Aerospace Sciences Meeting and Exhibit, Reno, NV, January 1998.

${ }^{19}$ Queen, E. M., Cheatwood, F. M., Powell, R. W., Braun, R. D., and Edquist, C. T., "Mars Polar Lander Aerothermodynamic and Entry Dispersion Analysis," Journal of Spacecraft and Rockets, Vol. 36, No. 3, May-June 1999.

${ }^{20}$ Gnoffo, P. A., Weilmuenster, K. J., Braun, R. D., and Cruz, C. I., "Influence of Sonic-Line Location on Mars Pathfinder Probe Aerothermodynamics," Journal of Spacecraft and Rockets, Vol. 33, No. 2, March-April 1996.

${ }^{21}$ Park, C., Howe, J. T., Jaffe, R. L., and Candler, G. V., "Review of Chemical-Kinetic Problems of Future NASA Missions, II: Mars Entries," Journal of Thermophysics and Heat Transfer, Vol. 8, No.1, January-March 1994.

${ }^{22}$ Roe, P. L., "Approximate Reimann Solvers, Parameter Vectors and Difference Schemes," Journal of Computational Physics, Vol. 43, No. 2, 1981.

${ }^{23}$ Yee, H. C., "On Symmetric and TVD Upwind Schemes," NASA TM-86842, September 1985.

${ }^{24}$ Baldwin, B. and Lomax, H., "Thin Layer Approximation and Algebraic Model for Separated Turbulent Flows," AIAA Paper 78-0257, 1978.

${ }^{25}$ Cheatwood, F. M., and Thompson, R. A., "The Addition of Algebraic Turbulence Modeling to Program LAURA," NASA TM-107758, April 1993.

${ }^{26}$ Whiting, E.E., Yen, L., Arnold, J.O., and Paterson, J.A., "NEQAIR96: Nonequilibrium and Equilibrium Radiative Transport and Spectra Program User's Manual," NASA RP-1389, Dec. 1996.

${ }^{27}$ Wright, M. J., Candler, G. V., and Bose, D., "Data-Parallel Line Relaxation Method for the Navier-Stokes Equations," AIAA Journal, Vol. 36, No. 9, 1998, pp. 1603-1609.

${ }^{28}$ MacCormack, R. W. and Candler, G. V., "The Solution of the Navier-Stokes Equations Using Gauss-Seidel Line Relaxation," Computers and Fluids, Vol. 17, No. 1, 1989, pp. 135-150.

${ }^{29}$ Yee, H. C., "A Class of High-Resolution Explicit and Implicit Shock Capturing Methods," NASA TM 101088, February 1989. 
${ }^{30}$ Menter, F.R., "Two Equation Eddy-Viscosity Turbulence Models for Engineering Applications,” AIAA Journal, Vol. 32, No. 8, 1994, pp. 1598-1605.

${ }^{31}$ Brown, J. L., "Turbulence Model Validation for Hypersonic Flows," AIAA Paper 2002-3308, AIAA Thermophysics Conference, St. Louis, MO, June 2002.

${ }^{32}$ Wright, M. J., Loomis, M. A., and Papadopoulos, P. E., "Aerothermal Analysis of the Project Fire II Afterbody Flow," Journal of Thermophysics and Heat Transfer, Vol. 17, No. 2, 2003, pp. 240-249.

${ }^{33}$ Wright, M. J., Prabhu, D. K., and Martinez, E. R., "Analysis of Afterbody Heating Rates on the Apollo Command Module, Part 1: AS-202," AIAA Paper No. 2004-2456, AIAA Thermophysics Conference, Portland, OR, June 2004.

${ }^{34}$ Faye-Petersen, R., Sarver, D., and Carroll, H., "Heat Transfer and Pressure Distributions at M = 8 on 0.028 Scale Models of the Viking Entry Vehicle," NASA CR 132413, Jul. 1972.

${ }^{35}$ Bose, D., Wright, M. J., and Palmer, G. E., "Uncertainty Analysis of Laminar Aeroheating Predictions for Mars Entries," Journal of Thermophysics and Heat Transfer, Vol. 20, No. 4, 2006, pp. 652-662.

${ }^{36}$ Milos, F. S., Chen, Y.-K., Congdon, W. M., and Thornton, J. M., "Mars Pathfinder Entry Temperature Data, Aerothermal Heating, and Heatshield Material Response," Journal of Spacecraft and Rockets, Vol. 36, No. 3, May-June 1999.

${ }^{37}$ Edquist, K. T, Wright, M. J., and Allen, G. A. Jr., "Viking Afterbody Heating Computations and Comparisons to Flight Data," AIAA Paper 2006-0386, AIAA Aerospace Sciences Meeting and Exhibit, Reno, NV, January 2006. 